Federal Reserve Bank of Dallas

Globalization and Monetary Policy Institute

Working Paper No. 20

http://www.dallasfed.org/assets/documents/institute/wpapers/2008/0020.pdf

\title{
An International Perspective on Oil Price Shocks and U.S. Economic Activity ${ }^{*}$
}

\author{
Nathan S. Balke \\ SMU and Federal Reserve Bank of Dallas \\ Stephen P. A. Brown \\ Federal Reserve Bank of Dallas \\ Mine K. Yücel \\ Federal Reserve Bank of Dallas
}

September 2008

\begin{abstract}
The effect of oil price shocks on U.S. economic activity seems to have changed since the mid-1990s. A variety of explanations have been offered for the seeming change — including better luck, the reduced energy intensity of the U.S. economy, a more flexible economy, more experience with oil price shocks and better monetary policy. These explanations point to a weakening of the relationship between oil prices shocks and economic activity rather than the fundamentally different response that may be evident since the mid-1990s. Using a dynamic stochastic general equilibrium model of world economic activity, we employ Bayesian methods to assess how economic activity responds to oil price shocks arising from supply shocks and demand shocks originating in the United States or elsewhere in the world. We find that both oil supply and oil demand shocks have contributed significantly to oil price fluctuations and that U.S. output fluctuations are derived largely from domestic shocks.
\end{abstract}

JEL codes: F41, Q43

* Nathan S. Balke, Department of Economics, Southern Methodist University, Dallas, TX 75275. nbalke@mail.smu.edu. Stephen P. A. Brown, Research Department, Federal Reserve Bank of Dallas 2200 North Pearl Street, Dallas, TX 75201. spa.brown@yahoo.com. Mine K. Yücel, Research Department, Federal Reserve Bank of Dallas, 2200 North Pearl Street, Dallas TX 75201. mine.k.yucel@dal.frb.org. The authors thank Mario Crucini, Fred Joutz, Luca Guerrieri, William Helkie,Lutz Kilian, Prakash Loungani, Erwan Quintin, Tara Sinclair, Mark Wynne and Carlos Zarazaga for helpful comments and discussions and Stefan Avdjiev and Zheng Zeng for capable research assistance. The authors retain all responsibility for omissions and errors. The views in this paper are those of the authors and do not necessarily reflect the views of the Federal Reserve Bank of Dallas or the Federal Reserve System. 


\section{An International Perspective on Oil Price Shocks and U.S. Economic Activity}

Abstract: The effect of oil price shocks on U.S. economic activity seems to have changed since the mid-1990s. A variety of explanations have been offered for the seeming change-including better luck, the reduced energy intensity of the U.S. economy, a more flexible economy, more experience with oil price shocks and better monetary policy. These explanations point to a weakening of the relationship between oil prices shocks and economic activity rather than the fundamentally different response that may be evident since the mid-1990s. Using a dynamic stochastic general equilibrium model of world economic activity, we employ Bayesian methods to assess how economic activity responds to oil price shocks arising from supply shocks and demand shocks originating in the United States or elsewhere in the world. We find that both oil supply and oil demand shocks have contributed significantly to oil price fluctuations and that U.S. output fluctuations are derived largely from domestic shocks.

\section{Introduction}

Since early 2003, the price of crude oil has nearly quadrupled, increasing from around $\$ 30$ per barrel (for West Texas Intermediate crude oil) to about $\$ 145$ in late summer 2008. In addition to little excess OPEC production capacity, an uncertainty premium brought about by geopolitical tensions, and a weak dollar; part of the strength in oil prices is attributed to the strength of Chinese, Indian, U.S. and European oil demand and to expectations that world oil demand will grow faster than supply over coming decades.

Since World War II, oil prices have gone hand-in-hand with U.S. recessions. In fact, nine of the ten post-WWII recessions have been preceded by episodes of sharply rising oil prices (Figure 1). The 1960 recession is the one exception.

Economic research has long documented a relationship between oil price shocks and slowing U.S. economic activity, with the consequences being slower GDP growth and possible recession, higher unemployment rates, and a higher price level. Some of the earlier studies include Pierce and Enzler (1974), Rasche and Tatom (1977), Mork and Hall (1980), Gisser and Goodwin (1986) and the Energy Modeling Forum 7 study documented in Hickman et al. (1987). 
Darby (1982), Burbidge and Harrison (1984), and Bruno and Sachs (1982, 1985) documented similar oil-price-economy relationships for countries other than the United States. Hamilton (1983) extended the analysis period to show that all but one of the U.S. post-WWII recessions were preceded by sharply rising oil prices. The apparent lack of a favorable response of economic activity to falling oil prices led to later studies—-such as Ferderer (1996), Hamilton (1996, 2003), Davis and Haltiwanger (2001) and Balke, Brown and Yücel (2002)—that allowed for an asymmetric relationship between oil price shocks and economic activity.

Several studies contend that the apparent relationship between oil price shocks and aggregate economic activity comes through monetary policy. Bohi $(1989,1991)$ and Bernanke, Gertler and Watson (1997) argue that a contractionary monetary policy response to oil price shocks accounted for much of the decline in aggregate economic activity following an oil price increase. In a somewhat different vein, Barsky and Kilian $(2001,2004)$ contend that swings between expansionary and contractionary monetary policy created cycles in which rising oil prices preceded but did not cause the economic downturns of the 1970s and 80s.

A number of other studies accord a much smaller role to monetary policy. Ferderer (1996) provides evidence that counter-inflationary monetary policy was only partially responsible for the real effects of oil price shocks over the period from 1970 to 1990. Davis and Haltiwanger (2001) showed that the effect of oil price shocks on employment growth were twice that of monetary policy shocks. Brown and Yücel (1999) argue that monetary policy wasn't necessarily contractionary. Hamilton and Herrera (2004) show that the reduction in interest rates necessary to offset the aggregate effects of rising oil prices are outside historical experience, and Herrera and Pesavento (forthcoming) find that monetary policy a had much smaller effect than that estimated by Bernanke, Gertler and Watson. 
Although the relationship between oil prices and economic activity seemed fairly robust and reasonably well understood by the mid-1990s, the relationship seemed to have weakened in the late 1990s and the 2000s — as shown by the relationship between oil prices and the cyclical component of GDP (Figure 2). The increase in oil prices in the early 1970s, the tripling of oil prices in 1979 and the sharp oil-price gains during the first Iraq war preceded declines in the cyclical component of real GDP. Since the mid-1990s, however, episodes of sharp oil price increases have not led declines in the cyclical component of real GDP — with the most noticeable period being since 2003 when oil prices more than quadrupled.

The apparent weakening or reversal of the past economic effects of oil price shocks has stimulated a new literature about why the U.S. economy might respond differently to rising oil prices in the 2000s than it did in the 1970s and early 80s. ${ }^{1}$ Contributions include Huntington (2003), CBO (2006), Blanchard and Gali (2007), Bodenstein, Erceg and Guerrieri (2007), and Segal (2007). The explanations include more stable aggregate demand (possibly the result of better luck or increased global financial integration), the reduced energy intensity of the U.S. economy, greater flexibility of the U.S. economy (including labor and financial markets), increased experience with energy price shocks, and better monetary policy.

Most of the explanations that have been offered for a changed response to oil price shocks treat oil price shocks as exogenous and point to quantitatively smaller effects rather than qualitatively different effects. But exogenous oil supply shocks need not be the only forces that push oil prices higher. Kilian (2007) identifies oil price shocks as arising from crude oil supply shocks, shocks to global oil demand and precautionary demand associated with uncertainty about

\footnotetext{
${ }^{1}$ A more general literature examines the increased stability of the U.S. economy since the mid-1980s, with explanations that include structural changes in the U.S. economy, better luck and improved monetary policy. See Kim and Nelson (1999a), McConnell and Perez-Quiros (2000), Blanchard and Simon (2001), Kahn, McConnell and Perez-Quiros (2002), Stock and Watson (2003), Bernanke (2004) and Boivin and Giannoni (2006).
} 
oil supply shortfalls. In a similar vein, Elekdag and Laxton (2007) argue that the current oil price increases are demand driven, while earlier increases in oil prices were supply driven. Productivity gains can boost global economic growth and push oil prices upward at the same time.

To analyze the effects of different types of economic shocks on aggregate economic activity and oil prices (while treating oil prices as endogenous), we develop a dynamic stochastic general equilibrium model of world economic activity. The model generally follows that of Backus, Kehoe and Kydland (1992) and Backus and Crucini (2000) and represents the world economy as two manufacturing countries and an oil-producing country. We depart from Backus and Crucini in two important ways. First, we represent all oil production and the evolution of oil reserves as endogenous. In our model, oil producers face dynamic tradeoffs when deciding how much oil to produce: higher production today reduces the oil reserves available in the future. Oil producers can invest to expand oil reserves, which increases future oil production capacity. Second, rather than calibrate the parameters of the model and use it for a simulation exercise, we use Bayesian methods to estimate the parameters of technology and preferences as well as the parameters for the stochastic process generating the exogenous shocks. In the process of estimating the parameters, we also estimate realizations for the unobserved shock processes.

The model allows us to examine empirically the effects of various types of shocks on oil markets and aggregate economic activity. These shocks include: oil supply shocks, oil reserve shocks, total factor productivity shocks, labor supply shocks, shocks to the economic efficiency of oil use, and shocks in investment demand originating in the manufacturing countries. The estimated model implies that shocks to oil production and reserves affect oil prices and output in 
a way that is reminiscent of oil supply shocks. Shocks in manufacturing countries look like a mixture of oil supply and demand shocks in the short run and oil demand shocks in the long run.

Historical decompositions suggest that much of the recent gains in oil prices can be attributed to oil "demand" shocks, but the episodes of dramatic oil price increases in the 1970s and early 1980s were attributable mainly to oil supply shocks. For the United States, the historical decompositions suggest these oil supply shocks had only moderate effects on economic growth. The poor economic performance in the 1970s and early 1980s appears to have resulted mainly from the confluence of negative shocks to total factor productivity and labor supply.

For recent years, the historical decompositions suggest that oil prices and U.S. real GDP have moved in the same direction for two reasons. Increases in total factor productivity have boosted U.S. GDP overwhelming the negative effects of oil supply shocks. Furthermore, improvements in the economic efficiency of oil use have simultaneously boosted U.S. GDP and the demand for oil.

\section{The Model}

Following Backus and Crucini (2000), we represent the world as three countries. Two of the countries each produce a final manufactured good. The third country produces oil, which is an intermediate good used in the production of the manufactured goods. Departing from Backus and Crucini, we treat oil production and the evolution of oil reserves in the oil-producing country as completely endogenous. ${ }^{2}$ Treating oil-production and pricing as endogenous in our framework allows us to more thoroughly examine the economic effects of total factor productivity shocks in the two manufacturing countries, as well as to consider the economic effects of oil supply shocks. The former is critical to distinguishing between productivity shocks

\footnotetext{
${ }^{2}$ Backus and Crucini represent oil production as having an exogenous component (OPEC) and an endogenous supply component via a labor-only technology.
} 
that could potentially increase world oil demand and prices from world oil supply shocks that increase oil prices. In addition to making the oil sector more dynamic than is represented in the Backus and Crucini model, we add three additional shocks that will help the model better capture actual fluctuations in economic activity: labor wedge shocks, oil wedge shocks, and investment shocks.

\subsection{Consumers}

In each of the three countries, consumers directly use the two manufactured goods and face a labor-leisure tradeoff. Accordingly, consumers in each country $j$ maximize lifetime utility:

$$
E_{j}=\sum_{t=0}^{\infty} \beta^{t} U\left(C_{j, t}, L_{j, t}\right) \quad \text { for } j=a, b, o
$$

where $\beta$ is a discount factor, $C$ is a CES aggregate of the manufactured goods $A$ and $B$, each of which is produced in countries $a$ and $b$, respectively, $L$ is leisure. Following Backus and

Crucini, $U\left(C_{j, t}, L_{j, t}\right)=\frac{\left(C_{j, t}^{\theta} L_{j, t}^{1-\theta}\right)^{1-\sigma}}{1-\sigma}$ for the manufacturing countries $j=a, b$; and $U\left(C_{o, t}, L_{o, t}\right)=\frac{C_{o, t}^{1-\sigma}}{1-\sigma}+\theta_{L, o} v\left(L_{o, t}\right)$ for the oil-producing country.

For the manufacturing countries, leisure is the amount of time available after supplying labor to manufacturing, $L_{j, t}=1-N_{j, t}$. For the oil-producing country, leisure is the amount time available after supplying labor to oil production and to reserve additions, $L_{o, t}=1-N_{o, t}-N_{x, t}$.

The CES consumption aggregate for each country is as follows:

$$
C_{j, t}=\left[\Psi_{j} A_{c, j, t}{ }^{1-\mu}+\left(1-\Psi_{j}\right) B_{c, j, t}{ }^{1-\mu}\right]^{1 /(1-\mu)} \quad \text { for } j=a, b, o
$$


where $A_{c, j, t}$ is country $j$ 's use of good A for consumption; $B_{c, j, t}$ is the country $j$ 's use of good B for consumption; $\Psi_{j}$ captures the weight households place on the consumption of goods $A$ and $B$; and $\mu$ is the elasticity of substitution between goods $A$ and $B$.

When estimating the model empirically, a preference shock is also added to the model that captures fluctuations in the wedge between the measured marginal rate of substitution between leisure and consumption and the marginal product of labor in the two manufacturing

countries. Specifically, $\frac{W_{j, t}}{P_{c, j, t}}=\omega_{N, j, t} M R S_{\text {leisure/consumption }, j, t}$ where $\omega_{N, t}$ is the labor wedge and $P_{C, j, t}$ is the consumption deflator in country $\mathrm{j}$. Changes in the wedge act like a labor supply shock. This shock could reflect not only changes in preferences but also changes in wage markups or changes in marginal tax rates. Hall (1997) and Chari, et al (2007) have argued that fluctuations in the wedge between marginal rate of substitution and marginal product of labor play an important role in labor market fluctuations.

\subsection{Manufacturing, Production and Investment}

In each of the manufacturing countries, output is a function of capital, labor, oil use and the technology available in each time period:

$$
Y_{j, t}=Z_{j, t} N_{j, t}^{\alpha}\left(\Psi_{k} K_{j, t}^{1-v}+\left(1-\Psi_{k}\right) O_{j, t}^{1-v}\right)^{\frac{1-\alpha}{1-v}} \quad \text { for } j=a, b
$$

where $Y_{j, t}$ is country $j$ output at time $t, K_{j, t}$ is capital, $N_{j, t}$ is labor, $O_{j, t}$ is oil use, and $Z_{j, t}$ is total factor productivity. One can think of this function as representing production as follows: oil and capital are used to produce capital services which are combined with labor to produce goods. The elasticity of substitution between capital and oil in the production of capital services is given by $1 / v$ and will generally be different than that between capital services and labor (which is unitary, given the Cobb-Douglas representation of the latter relationship). 
As is done for the labor market, when taking the model to the data we add a stochastic wedge between the measured marginal product of oil and the relative price of oil. The oil wedge, $\omega_{o, j, t}$, is defined such that $M P_{o, j, t}=\omega_{o, j, t} \frac{P_{o, t}}{P_{j, t}}$ where $M P_{o, j, t}$ is the (measured) marginal product of oil in the production of country j's output. The wedge could reflect policies that affect the true price to firms of using oil (for example, taxes or environmental regulations). The wedge also could reflect a difference between our model-based measure of the marginal product of oil and its true productivity — with a greater measured value of marginal product relative to true marginal product yielding a higher value of $\omega_{o, j, t}$, assuming the real oil price is unchanged. The wedge acts as an additional source of fluctuations in oil demand in our empirical model.

Similar to that for consumption, the CES investment aggregate for each manufacturing country is as follows:

$$
I_{j, t}=\left[\Psi_{j} A_{i, j, t}{ }^{1-\mu}+\left(1-\Psi_{j}\right) B_{i, j, t}{ }^{1-\mu}\right]^{1 /(1-\mu)} \quad \text { for } j=a, b
$$

where $A_{i, j, t}$ is country $j$ 's use of good A for investment, $B_{i, j, t}$ is the country $j$ 's use of good B for investment. Capital accumulation in each of the manufacturing countries takes into account depreciation and investment as follows:

$$
K_{j, t+1}=(1-\delta) K_{j, t}+\Phi\left(I_{j, t} / K_{j, t}\right) K_{j, t}+Z_{K, j, t} \quad \text { for } j=a, b
$$

where $\delta$ is the depreciation rate and $I_{j, t}$ is investment. $\Phi\left(I_{j, t} / K_{j, t}\right)$ is the rate at which investment goods become capital and reflects adjustment costs in changing the stock of capital with $\Phi^{\prime}()>$.0 and $\Phi^{\prime \prime}()<.0 . Z_{K, j, t}$ is a capital accumulation shock (similar to an additive productivity shock to investment). One can think of this shock as reflecting shocks to investment demand that are unrelated to the future marginal product of capital. 


\subsection{Oil Production and Reserves}

The production of oil is a function of oil reserves, labor, and the technology available in each time period:

$$
Y_{o, t}=Z_{o, t}\left(\Psi_{x} X_{t}^{1-\rho_{o}}+\left(1-\Psi_{x}\right) N_{o, t}^{1-\rho_{o}}\right)^{\frac{1}{1-\rho_{o}}}
$$

where $Y_{o, t}$ is oil production at time $t, X_{t}$ is oil reserves, $N_{o, t}$ is the labor used in oil extraction, and $Z_{o, t}$ is the oil production technology. Note that in time period $\mathrm{t}, X_{t}$ is predetermined.

The evolution of oil reserves reflects both additions to reserves and the depletion due to production. Gross additions to reserves are made through use of investment goods and labor:

$$
G_{t}=G\left(I_{x, t}, N_{x, t}, Z_{x, t}\right)=Z_{x, t}\left(\Psi_{g} I_{x, t}^{1-\rho_{g}}+\left(1-\Psi_{g}\right) N_{x, t}^{1-\rho_{g}}\right)^{1 /\left(1-\rho_{g}\right)}
$$

where $I_{x, t}$ is the capital investment for reserve additions, $N_{x, t}$ is labor used for reserve additions, and $Z_{x, t}$ reflects total factor productivity in the production of reserves. Net additions to reserves reflect not only loss of reserves due to production but also an adjustment cost mechanism similar to that employed by capital:

$$
X_{t+1}=X_{t}+\Phi_{g}\left(G_{t} / X_{t}\right) X_{t}-Y_{o, t}
$$

where $\Phi_{g}{ }^{\prime}()>$.0 and $\Phi_{g}{ }^{\prime \prime}()<$.0 . Note that in the steady state, $G=Y_{o}, \Phi_{\mathrm{g}}(\mathrm{G} / \mathrm{X})=\mathrm{G} / \mathrm{X}$, and $\Phi_{g}{ }^{\prime}(G / X)=1$. One can view reserves in our model as representing total capital in the oilproducing sector, which reflects oil-production infrastructure (capital) as well as oil in the ground. The depletion of reserves (i.e., the depreciation of oil-producing capital) depends on how much oil is produced.

Similar to that for the manufacturing countries, the CES investment aggregate for the oil reserve additions is as follows: 


$$
I_{x, t}=\left[\Psi_{x} A_{i, x, t}{ }^{1-\mu}+\left(1-\Psi_{x}\right) B_{i, x, t}{ }^{1-\mu}\right]^{1 /(1-\mu)}
$$

where $A_{i, x, t}$ is the use of the country $a$ good in the process of making reserve additions, and $B_{i, x, t}$ is the use of the country $b$ good in the process of making reserve additions.

\subsection{International Market Clearing Constraints}

In each period of time, the total quantities of each of the three goods must be completely used:

$$
\begin{gathered}
Y_{a, t}=A_{c, a, t}+A_{c, b, t}+A_{c, o, t}+A_{i, a, t}+A_{i, b, t}+A_{i, o, t} \\
Y_{b, t}=B_{c, a, t}+B_{c, b, t}+B_{c, o, t}+B_{i, a, t}+B_{i, b, t}+B_{i, o, t} \\
Y_{o, t}=O_{a, t}+O_{b, t}
\end{gathered}
$$

In addition, market-clearing prices and wages must be established.

\subsection{Exogenous Shocks}

There are ten exogenous driving forces in our model. Eight shocks originate in the two manufacturing countries. For each manufacturing country, there are shocks to total factor productivity, the labor wedge, the oil wedge and investment. The other two shocks originate in the oil-producing country. They are a technology shock to oil production and a technology shock to the production of oil reserves. With the exception of total factor productivity shocks, we assume that the (logs of the) exogenous driving forces follow independent first-order autoregressive processes. Following Backus and Crucini (2000), we allow total factor productivity to be correlated across manufacturing countries, both contemporaneously and with a lagged spillover. Unlike Backus and Crucini, the stochastic processes for these variables are not assumed to be the same across the two manufacturing countries. 


\subsection{Oil Supply Shocks}

As discussed above, the model's implementation of oil demand is similar to that found in Backus and Crucini (2000). On the supply side, the current model differs from Backus and Crucini by capturing both oil production and reserves.

Maximizing the representative agent's utility in the oil-producing country, taking prices as given, yields the following decisions rules for the production of oil and reserves. Oil production is determined so that:

$$
p_{o, t}=p_{x, t}+m c_{o, t}
$$

where $p_{o, t}$ is the price of oil (in terms of the numeraire good), $p_{x, t}$ is the price of reserves (user cost of oil), and $m c_{o, t}$ is the marginal cost of producing oil in time period t. Given that the stock of reserves is fixed in time $\mathrm{t}, m c_{o, t}=w_{o, t} / m p_{l, t}^{o}$ where $w_{o, t}$ is the wage (in terms of the numeraire good) in the oil-producing country and $m p_{l, t}^{o}$ is the marginal product of labor in the oil-producing country. The first order condition for the production of reserves is given by:

$$
p_{x, t}=\underset{t}{E}\left[M_{t+1}\left\{\left(p_{o, t+1}-p_{x, t+1}\right) m p_{x, t+1}^{o}+p_{x, t+1}\left(1+\Phi_{g, t+1}-\Phi_{g, t+1}^{\prime} \frac{G_{t+1}}{X_{t+1}}\right)\right\}\right]
$$

where $M_{t+1}$ is the stochastic discount factor and

$\left\{\left(p_{o, t+1}-p_{x, t+1}\right) m p_{x, t+1}^{o}+p_{x, t+1}\left(1+\Phi_{g, t+1}-\Phi_{g, t+1}^{\prime} \frac{G_{t+1}}{X_{t+1}}\right)\right\}$ is the payoff of having more reserves next period. The term $\left(p_{o, t+1}-p_{x, t+1}\right) m p_{x, t+1}$ is the value of using those reserves to produce oil next period while $p_{x, t+1}\left(1+\Phi_{g, t+1}-\Phi_{g, t+1}^{\prime} \frac{G_{t+1}}{X_{t+1}}\right)$ is the value of additional reserves at the end of 
the next period. The term $\Phi_{g, t+1}-\Phi_{g, t+1}^{\prime} \frac{G_{t+1}}{X_{t+1}}$ reflects the effect on adjustment costs next period of having more reserves available.

How do the two oil technology shocks affect oil output and prices? For a given level of inputs, a negative technology shock to oil production, $Z_{o, t}$, will lower the production of oil and increase marginal costs- - lowering output and raising the price. To the extent that the shock is persistent, it will result in higher prices for reserves both currently and in the future, stimulating the development of reserves in the future. These reserve additions will stimulate future oil production.

Although a negative technology shock to the development of reserves, $Z_{x, t}$, has no direct effect on contemporaneous oil supply (recall that $X_{t}$ is predetermined in time period $\mathrm{t}$ ), it can affect current oil prices and output. A negative shock to the development of reserves will mean fewer reserves in the future, which will reduce future oil production and raise future oil prices. Taken alone, this shock would boost the price of reserves and, hence, oil prices today. On the other hand, a negative technology shock in the development of reserves can free up labor for oil production, which could result greater current production and lower oil prices. The total effect on current oil production and prices depends on the comparative strengths of these two effects.

Modeling the oil-producing country as a price-taker is contrary to the view that OPEC sets production quotas or oil prices. As long as price is a constant mark up over costs, however, such an assumption will not have an appreciable effect on our analysis. Indeed, as we treat the price of reserves, $p_{x, t}$, as not directly observed, fluctuations in this variable will reflect any 
fluctuations in the mark-up of oil prices over marginal costs. ${ }^{3}$ Thus, changes in OPEC's price setting stance will in part be captured by our measures of technology shocks to oil production and reserve development. An exogenous cut in OPEC oil production, perhaps for geopolitical reasons, would look like a negative technology shock to oil production. ${ }^{4}$

\section{Model Solution and Estimation.}

To solve the model for a given set of parameters, we log-linearize the first order conditions of the social planner's problem around the deterministic steady state and solve the resulting linear rational expectations model as in Blanchard and Kahn (1980). Rather than calibrate the parameters, we use Bayesian methods to estimate the parameters of technology, preferences, and the stochastic processes generating the exogenous shocks.

As in Backus and Crucini, we take the United States to be one of the manufacturing countries in the model. The other manufacturing country denoted below by ROW, we take to be the OECD countries (less Mexico and the United States) plus Brazil, China, and India. We take the time interval of the model to be quarterly and include eight quarterly time series in the estimation of the model. These inclue: real oil prices (deflated by the U.S. GDP deflator), world oil production, U.S. real GDP, U.S. real consumption, U.S. real investment, U.S. hours, U.S. oil consumption and the relative price of imports to the United States.

While the relative price of U.S. imports, U.S. oil consumption and world oil production provide the information about economic activity in the ROW, it would be useful to include more direct information on economic activity in ROW. Unfortunately, there are not quarterly data of sufficient length for many countries to construct a quarterly series for the ROW. Because our

\footnotetext{
${ }^{3}$ Petroleum Intelligence Weekly and the Oil and Gas Journal provide some data on the sales of reserves, but these prices may not be representative of overall market conditions because most reserves - particularly those of OPECare not traded, and the value of reserves may vary considerably with the characteristics of the reserves.

${ }^{4}$ This abstracts from the cross-country wealth effect of an increase in the markup of oil prices.
} 
estimation procedure readily handles the use of mixed frequency data (see appendix), however, we add annual ROW output and investment (in constant dollars) as two additional observation equations. Thus, taken together we have eight quarterly observation equations and two annual observation equations. ${ }^{5}$ Our sample period runs from 1970 through 2006.

The linearized DSGE model links the observed time series and the underlying driving processes that result in deviations from the steady state. ${ }^{6}$ Markov Chain Monte Carlo methods similar to those of Lubik and Schorfheide (2004) and Smets and Wouters (2007) are employed to estimate the posterior distribution of the parameters. ${ }^{7}$ In the process of estimating the posterior distribution of the parameters, we also estimate a posterior distribution for the unobserved shock processes. These estimates allow us to decompose movements in actual observables into contributions due to various exogenous shocks.

\subsection{Prior and posterior distributions of the structural parameters.}

In implementing the Bayesian estimation strategy, we must specify prior distributions for the structural parameters (parameters of technology and preferences) and the parameters of the stochastic processes of the ten exogenous driving forces. For most of the structural parameters for the two manufacturing countries, we set the mode of the prior distribution to be equal to the values set in Backus and Crucini. For the oil-producing country, we use information on the ratio of oil production to reserves, $\frac{Y_{0}}{X}$, labor share in the production of oil, and the ratio of oil price to

\footnotetext{
${ }^{5}$ For the United States and world oil, we find substantially similar results to those reported below when the model is not required to fit annual output and investment data for rest of the world. The principal difference is that use of the rest of world data allows a better identification of the individual sources of rest-of-world shocks.

${ }^{6}$ The logs of U.S. real GDP, consumption, investment, hours, oil consumption; relative price of imports to the United States; rest of world output and investment; and world oil production are linearly detrended. The logs of real oil price are demeaned.

${ }^{7}$ We use the random walk Metropolis-Hastings sampler to generate draws from the posterior distribution. The transition equation in the Markov Chain depends on the Hessian of the posterior distribution evaluated at the posterior mode and shocks drawn from a t-distribution with five degrees of freedom. We use 105,000 draws in our sampler with 100,000 draws as the burn in period.
} 
reserve price, $\frac{p_{o}}{p_{x}}=\frac{p_{o}}{p_{0}-m c_{0}}$, to help set the prior distributions of the parameters. As for how much weight to place on the prior distribution versus the data when estimating the posterior distributions, we divide the parameters into roughly three groups. Parameters like the discount factor or those that reflect shares of steady state values (for example, output elasticity of labor equals labor's share in GDP) have relatively tight priors. Parameters that reflect elasticities of substitution or adjustment costs for capital and reserves have more diffuse priors. Finally, a third group of parameters, namely the parameters of the stochastic processes governing the driving forces have relatively uninformed priors - as we have very little direct prior information concerning these stochastic processes.

Table 1 displays the prior and estimated posterior distributions of the structural parameters. For many parameters, using the information in the data results in a substantial shift in the posterior distribution relative to the prior distribution; for most parameters the posterior distribution is substantially tighter than the prior distribution. Not surprisingly given the tight priors for these parameters, the posterior distributions for the discount factor, labor's share in manufacturing country GDP, the share of home and foreign goods, and the depreciation rate on capital are close to the values assumed in Backus and Crucini.

Our posterior distribution suggests an estimate of the intertemporal elasticity of substitution which is similar to that typically assumed in the macroeconomics literature. The posterior distribution also suggests an elasticity of substitution between domestic and the foreign good that is substantially lower than that assumed in Backus and Crucini. ${ }^{8}$ On the other hand, the elasticity of substitution between oil and capital is slightly larger than in Backus and Crucini.

\footnotetext{
${ }^{8}$ Given that Backus and Crucini calibrate their parameters to data for the United States and other OECD countries, it is not surprising that our estimated parameters take different values. In addition, the dramatic swings in the relative
} 
The posterior distributions for all three of these elasticities are substantially "tighter" than their prior distributions. The posterior distribution for the elasticities of substitution in the oil production and reserve production technologies are still relatively "diffuse" suggesting the data are not too informative about these parameters. Finally, the adjustment costs for capital are estimated to be substantially higher than those for oil reserves suggesting that it is easier to add to reserves than it is to add to capital in the manufacturing country.

Table 2 presents the prior and posterior distributions for the stochastic processes governing the exogenous variables in the model. Given that prior distributions were relatively uninformative, the data have a lot to say about these variables. With the exception of ROW investment demand shocks, the autoregressive parameters are quite high suggesting that shocks are very persistent. The standard deviation of shocks to oil production and oil reserves are relatively large compared to shocks in total factor productivity and investment shocks in the manufacturing countries. The standard deviation of oil wedge shocks in the two manufacturing countries is very large suggesting that these two variables may be an important source of shocks to world oil demand. On the other hand, the estimated spillover in total productivity is relatively small. Finally, the variances of ROW shocks, with the exception of the investment shock, are estimated to be larger than U.S. shocks.

\subsection{Model Evaluation}

To evaluate the relative fit of the model, we compare our benchmark model to a model in which the structural parameters are set to the values assumed by Backus and Crucini (the parameters of the shock processes are estimated as in the benchmark model) and to a state space 
model in which the state equation is a VAR(1) with relatively uninformed priors. ${ }^{9}$ We use a state space-VAR(1) rather than a traditional VAR(1) model for comparison because we have only annual data for rest-of-world output and investment.

To assess our model's overall "goodness of fit", we construct marginal likelihoods and Bayes factors for the three models. ${ }^{10}$ These are presented in Table 3. Our benchmark model appears to "fit" the data better than the two alternative models. As mentioned above, with the exception of the elasticity of substitution between domestic and foreign goods, the modes of the posterior distribution for most of the structural parameters in the benchmark model are similar to the values assumed in Backus and Crucini. However, because of the large swings in the relative import price over our sample, a low value for the elasticity of substitution between domestic and foreign goods in the benchmark model substantially improves the fit of the model. The benchmark model fits better than the state space-VAR(1) model in part because relatively diffuse priors are assumed for the latter model's vastly greater number of parameters. Unfortunately, we were unable to conceive of "naturally suggestive" non-diffuse prior distributions for the reduced form state space model that yielded an improvement over the model with diffuse priors. ${ }^{11}$

\section{Impulse Responses}

To obtain a better picture of what the model implies about oil shocks and economic activity, we examine how oil markets and real U.S. GDP respond to a variety of shocks, including a negative oil production shock, a negative oil reserve shock, a positive total factor productivity shock, a positive labor wedge shock, a positive oil wedge shock, and a negative U.S.

\footnotetext{
${ }^{9}$ The benchmark and Backus and Crucini models are evaluated assuming the same prior distributions. Recall that Backus-Crucini parameters are the modes of the prior distributions for the benchmark model.

${ }^{10}$ We use the harmonic mean estimator proposed by Geweke (1999) with a truncation probability of 0.8 .

${ }^{11}$ State space models with a higher order VAR describing the state equations quickly become quite large as one adds lags. The state space-VAR(1) model contains 155 parameters while a VAR(2) model contains 255 parameters. We experimented with imposing Minnesota type priors, but these priors did not improve the performance of the state space-VAR(1) model in this particular application.
} 
investment demand shock. Different types of shocks can yield similar responses in oil prices and production. In many cases, the longer-term dynamics of a shock differ from its short-run effects.

As modeled here, a shock is an unexpected and temporary deviation in a series away from its long-term trend. Such shocks show persistence, but eventually dissipate. For each series, we report impulse responses for the mean, $5^{\text {th }}$ and $95^{\text {th }}$ percentile of the posterior distribution.

\subsection{Effects on the Oil Market}

We find that an oil production shock yields oil-market dynamics that are like the classic supply shock envisioned in most economic research. As shown in Figure 3A, an oil production shock boosts the price of oil. As the shock dissipates, the price of oil returns toward its longterm steady state.

An oil reserve shock yields initially leads to slightly higher production and lower prices, as the negative technology shock to reserve production frees up labor for oil production. Over the longer-term, however, lower reserves yield reduced oil production and higher oil prices.

From the perspective of oil-market dynamics, a total factor productivity shock in the United States initially looks similar to an oil-supply shock. The price of oil is pushed upward and oil production is initially reduced as investment is redirected to the manufacturing countries. Over the longer-term, increased oil demand is translated into increased oil production, but oil production lags behind the growth of manufacturing, which sustains higher oil prices.

An increase in the labor wedge acts like a negative shock to labor supply that reduces U.S. employment and output. As shown in Figure 3B, such a shock initially looks like a supply shock for oil—weaker economic activity reduces oil consumption, but the relative price of oil is 
pushed upward as U.S. firms substitute oil for labor. Over the longer-term, a decline in manufacturing output dominates, and the oil price and output fall.

An increased oil wedge could be the result of higher energy taxation or reduced economic efficiency in the use of oil. An increased U.S. oil wedge has relatively simple dynamics. The initial and longer-term effects are a negative shock to oil demand that depresses the price of oil and reduces oil output.

A positive investment shock in the United States generates complicated dynamics in the world oil market. The initial responses look like an oil supply shock. The relative price of oil is pushed upward and oil production falls. This is due primarily to a decline in the demand for U.S. output, and as a result the relative price of oil rises. Over the longer-term, the relative price of oil remains high but oil production is increased.

As can be seen, interpreting the dynamics of the oil market through oil prices and production is fraught with difficulty. Different types of economic shocks can yield similar outcomes in the oil market, and the long-term dynamics of a particular shock can be different from the short-term effects. These results suggest that additional information about the source of oil price shocks might be gleaned by examining how the shocks affect overall economic activity.

\subsection{Effects on U.S. Economic Activity}

As shown in Figure 4, a negative oil-production shock reduces U.S. output. The negative effects on economic activity gradually moderate over time. Similarly, a negative shock to oil reserves reduces U.S. output.

As expected, a favorable shock to total factor productivity in the United States boosts U.S. output. The gains in output are driven directly by increased productivity — and also by the increased investment, work and oil use that are stimulated by enhanced productivity. Although 
the estimated parameter for total productivity spillovers is relatively small, a foreign productivity gain yields small gains in U.S. output - with those gains the result of productivity spillovers and increased exports, investment and labor.

An increase in the U.S. labor wedge (or decrease in labor supply) reduces U.S. output. An increase in the labor wedge abroad also generates U.S. output losses — with those losses the result of reduced trade.

Both a decrease in the economic efficiency of U.S. use of oil (an increased oil wedge) and a negative investment demand shock in the United States reduce U.S. output. Foreign shocks in these variables stimulate U.S. output by making oil and investment capital more available to the United States.

\subsection{Oil Price Shocks and U.S. Economic Activity}

The impulse response functions show avenues through which oil price movements and U.S. GDP may be negatively related, positively related or seemingly unrelated. As expected, oil supply shocks generate a negative relationship between oil prices and U.S. economic activity. The model reflects oil supply shocks originating from both production and reserves. Taken together, these two supply shocks imply that the estimated mean oil price elasticity of U.S. real GDP is -0.018 . The interior 90 percent of the posterior distribution for the elasticity is -0.012 to -0.029 . These estimates are at the lower end of the range, -0.012 to -0.12 , found by previous empirical research for the United States. ${ }^{12}$

Shocks to the ROW oil wedge and U.S. capital accumulation also generate an inverse relationship between oil price fluctuations and U.S. output. In essence, a positive capital accumulation shock implies less investment is needed to reach the desired level of capital stock.

\footnotetext{
${ }^{12}$ See Jones, Leiby and Paik (2004). If the model is not asked to fit annual data for the rest of the world, somewhat higher estimates of the oil price elasticity of real GDP are obtained.
} 
Thus, the capital accumulation shock works like a negative investment demand shock and leads to lower U.S. output. In contrast, shocks to U.S. and ROW total factor productivity, the U.S. oil wedge, and ROW investment generate a positive relationship between oil price and U.S. GDP. Shocks to the labor wedges affect economic activity but have relatively little effect on oil prices.

\section{Historical Decompositions}

Historical decompositions show the contribution of each shock to the evolution of oil prices and U.S. GDP. In each of the figures, we represent the actual history of the variable over the past 37 years and the mean, $5^{\text {th }}$ percentile and $95^{\text {th }}$ percentile of the posterior distribution. The extent to which the posterior distribution moves with the historical series shows the extent to which the variable explains the historical movement.

\subsection{Real Oil Price}

Figures 5A-C display historical decomposition for real oil prices. Figure 5A summarizes the relative contributions of oil supply shocks, oil demand shocks and demand shocks from the U.S. and ROW to world oil price movements. The historical decomposition suggests that the rapid rise in the oil price from 1973 through the early 1980s was largely driven by oil supply shocks, with ROW demand shocks contributing to the oil price increases in the early 1980s. The decline in oil prices in the mid-1980s and again during 1998 and 1999 appears to be equally driven by oil supply and oil demand shocks. Much of the recent run-up in oil prices is demand driven — with roughly equal contributions from the United States and the ROW.

Among the two types of oil supply shocks, shocks to oil production are much more important to the evolution of world oil prices than are oil reserve shocks (Figure 5B). On the

demand side, shocks to the economic efficiency of oil use in both the United States and the ROW are relatively important (Figure 5C). Total factor productivity shocks make only a small 
contribution to oil price movements. For oil price movements, shocks to the U.S. and ROW labor wedges and investment demand are relatively unimportant.

\subsection{U.S. Output}

Figures 6A-C display historical decomposition for U.S. real GDP. Figure 6A summarizes the relative contributions of oil, domestic, and foreign shocks on U.S. real GDP. As shown in the figure, the model implies that domestic shocks are largely responsible for U.S. output fluctuations. Oil shocks contribute only moderately to U.S. output fluctuations, and ROW shocks are much less important.

As shown in Figures 6B-C, shocks to U.S. total factor productivity and to the labor wedge appear to be the most important sources of domestic shocks for real U.S. GDP. Strongly related to traditional business cycle fluctuations, the labor wedge contributes substantially to output declines in every recession in our sample. This is consistent with previous findings such as Hall (1997) and Chari, et al. (2007). Shocks to the U.S. oil wedge and investment demand, while not as important as productivity and labor supply shocks, do contribute to output fluctuations over our sample.

\subsection{Oil Prices and Sources of U.S. Economic Fluctuations}

Taken together, figures 5 and 6 provide an interesting perspective on recent economic history. The historical decompositions show that oil production shocks are the most important source of oil price fluctuations and a moderate source of U.S. economic fluctuation. Unfavorable oil production shocks boost oil prices and moderately reduce U.S. GDP. The historical decompositions also show that shocks originating in the United States are a moderately important source of oil price fluctuations and the most important source of U.S. output fluctuations. 
Changes in total factor productivity, the labor wedge, the oil wedge, and investment demand have all contributed to fluctuations in U.S. real GDP. Of these shocks, those arising from the oil wedge contribute the most to movements in world oil prices. Consistent with the impulse response functions, shocks originating in the United States generally contribute to a positive relationship between oil prices and U.S. output—although the impulse response functions for shocks to the labor wedge and investment demand show much greater effect on U.S. economic activity than on oil prices.

The historical decompositions also show that shocks originating abroad that are unrelated to oil supply are a fairly important source of world oil price fluctuation without having much net effect on U.S. output. The oil price gains driven by foreign demand shocks do not have the generally negative effect on U.S. economic activity that results from oil supply shocks. Although the gains from trade and productivity spillovers to the United States are small, they seem to offset any economic losses that arise from the effects of higher oil prices. ${ }^{13}$

\subsection{Comparing the 1970s and the 2000s}

The relatively poor U.S. economic performance in the mid-1970s though the early 1980s appears to have been bad luck - that is, a confluence of negative factors. Oil supply shocks contributed moderately to the poor economic performance, as did shocks to total factor productivity and the labor wedge. In the late 1970s, the increased economic efficiency of U.S. oil use — as reflected in reduced oil wedge — provided a slight stimulus to U.S. economic activity while boosting oil prices. This favorable effect on U.S. economic activity was dominated by the negative factors at work during the time.

\footnotetext{
${ }^{13}$ When the model's structural parameters are set to values assumed by Backus and Crucini, oil supply shocks and ROW shocks contribute more to U.S. GDP movements. Recall that the mode of the posterior distribution for the elasticity of substitution between home and foreign goods is 0.34 in our model, while Backus and Crucini set it at
} 
Our findings for the 1970s are generally consistent with Blanchard and Gali (2007), as well as Nordhaus (2004), Greenwood and Yorukoglu (1997), and Samaniego (2006). Blanchard and Gali find the poor U.S. economic performance of the 1970s owes a combination of adverse oil price shocks and other bad luck. Nordhaus shows that the 1970s productivity slowdown was concentrated in the most energy-intensive sectors, and Greenwood and Yorukoglu and Samaniego variously attribute some of the negative productivity shocks of that era to significant learning costs associated with the adoption of new technologies and the necessity of plant-level reorganization. ${ }^{14}$

For more recent years, Blanchard and Gali find rising oil prices had small negative effects on output that were generally dwarfed by the effects of other positive shocks. Although we do find some evidence that unfavorable oil supply shocks weakened U.S. economic activity in recent years, our findings are somewhat different. We find the strong growth in U.S. real GDP during the 1990s and 2000s reflects several different sources. The first contribution was an investment boom in the early and mid-1990s. The second contribution came from increased total factor productivity, which began to make an impact in the mid-1990s and mostly continues through the end of the sample in 2006. Gains in the economic efficiency of U.S. oil use also provided a slight stimulus to U.S. economic activity while boosting oil prices. Because these gains in total factor productivity and the economic efficiency of oil use also helped drive oil prices higher, we find evidence of relatively benign mechanisms in which oil prices and economic activity were both driven upward by the same forces. At the same time, foreign productivity shocks boosted oil prices without much net effect on U.S. economic activity.

1.5. A higher elasticity of substitution implies that for a given change in relative prices, the quantity response is greater.

${ }^{14}$ Some of the negative productivity shocks of the 1970s may also be the result of the new and relatively inefficient environmental regulation introduced during that era. 


\subsection{Sources of ROW Fluctuations}

Although our focus has been primarily on oil price movements and U.S. economic activity, our model does have something to say about fluctuations in the rest of the world. Figure 7 plots the mean (and $5^{\text {th }}$ and $95^{\text {th }}$ percentiles) of the posterior distribution for the total contribution of all the shocks to ROW GDP. Figure 7 also shows the source of the ROW fluctuations as originating from the oil sector, U.S. shocks, and ROW shocks. Even though the model is quarterly and the ROW data are annual, the model tracks movements in ROW GDP relatively well. As the figure shows, oil shocks explain relatively little of the fluctuations in ROW GDP; the largest contribution occurred in the early 1980s. Shocks originating in the United States contribute even less to fluctuations in ROW GDP. Fluctuations in ROW output fluctuations are driven primarily by ROW shocks, with TFP shocks and labor wedge shocks being the most important (details available upon request). The dramatic gain in ROW GDP at the end of the sample can be mostly attributed to increases in ROW TFP.

\section{Conclusions}

Oil prices have nearly quadrupled since early 2003, but U.S. economic activity expanded rapidly for a number of those years - even as oil prices increased. As we have seen, the factors driving oil price gains also determine the effect on overall economic activity. Oil supply shocks alone do not explain the changes in economic activity or oil markets over the past decade. Our historical decompositions show that shocks to oil production, oil reserves, the economic efficiency of U.S. and foreign energy use, U.S. and foreign investment and U.S. total factor productivity have contributed to oil price movements and fluctuations in real economic activity 
over the past 37 years. The labor wedge is an important source of U.S. economic fluctuation without much effect on oil prices.

Of these factors, increased U.S. total factor productivity and the improved economic efficiency in the U.S. use of oil seem to have contributed to a positive relationship between oil prices and U.S. real GDP in recent years. During the same period, economic shocks originating abroad also seem to have generally contributed to an increase in world oil prices without negative consequences for U.S. output. Better luck - in the form of a confluence of oil supply shocks and favorable shocks to U.S. economic activity - has added to the appearance of a more favorable relationship between oil prices and economic activity.

In contrast with the recent experience, the 1970s and early 1980s saw rising oil prices and a poor U.S. economic performance. Negative oil supply shocks and increased foreign oil demand toward the end of the period pushed oil prices upward. The oil-supply shocks contributed to the relatively poor U.S. economic performance, but the United States also experienced weakening total factor productivity, which may have been the result of adjustment to new capital that embodied information technology. By not taking into account these declines in total factor productivity, the earlier literature on the negative effects of oil-price shocks may have overestimated the magnitude that such shocks have on economic activity.

As we have seen, oil price increases arising from productivity gains and other shocks can have a substantially different effect on oil markets and economic activity than those arising from oil supply shocks. Unfavorable oil supply shocks boost oil prices and reduce aggregate economic activity. Favorable domestic productivity shocks boost GDP while pushing oil prices upward. Favorable foreign productivity shocks may be mildly beneficial, as the increased trade and technology spillovers more than offset the negative effects of higher oil prices. 
These substantially different effects have important implications for our understanding of the relationship between oil prices and aggregate economic activity. In a world where strong economic growth and rising oil demand in China and India have combined with more moderate gains in Europe and the United States to put tremendous upward pressure on oil prices, different types of economic shocks have different consequences for oil prices and economic activity. Some shocks can result in a positive relationship between oil prices and aggregate economic activity. The negative correlation that seemed to characterize the relationship between oil prices and economic activity in the 1970s and early 80s does not well describe a global economy where oil price gains are being driven by forces other than unfavorable oil supply shocks. 


\section{Technical Appendix}

\section{A. Details of the Model}

Manufacturing countries a and $\mathrm{b}$

We write the log linearized (around the deterministic steady state) first order conditions for the social planners' problem. From the FOCs with respect to $A_{c, j, t}, j=a, b$ :

$(\theta(1-\sigma)-(1-\mu)) \hat{C}_{j, t}-(1-\theta)(1-\sigma) \frac{N^{j}}{1-N^{j}} \hat{N}_{j, t}-\mu \hat{A}_{c, j, t}-\hat{p}_{a, t}=\hat{z}_{u, j, t}, j=a, b$

where $N^{j} /\left(1-N^{j}\right)$ is the labor/leisure ratio for country $\mathrm{j}, \hat{p}_{a, t}$ is the (shadow) price of good A, and $\hat{z}_{u, j, t}$ is a preference shock that will be the source of the wedge between the measured marginal rate of substitution between consumption and leisure and the marginal product of labor. Similarly, from the FOCs with respect to $B_{c, j, t}, j=a, b$ :

$$
(\theta(1-\sigma)-(1-\mu)) \hat{C}_{j, t}-(1-\theta)(1-\sigma) \frac{N^{j}}{1-N^{j}} \hat{N}_{j, t}-\mu \hat{B}_{c, j, t}-\hat{p}_{b, t}=\hat{z}_{u, j, t}, j=a, b
$$

Also,

$$
\hat{C}_{j, t}-s_{a, j} \hat{A}_{c, j, t}-\left(1-s_{a, j}\right) \hat{B}_{c, j, t}=0, j=a, b,
$$

where $s_{a, j}=\Psi_{j}\left(A_{c, j} / C_{j}\right)^{1-\mu}$ is the steady state expenditure share in country $\mathrm{j}$ on good a. Linearized FOCs for labor for country $a$ and $b$ are:

$\hat{Y}_{j, t}+\hat{p}_{j, t}-\theta(1-\sigma) \hat{C}_{j, t}+\left[((1-\theta)(1-\sigma)-1) \frac{N^{j}}{1-N^{j}}-1\right] \hat{N}_{j, t}=0, \quad j=a, b$.

The linearized FOCs for oil inputs for country a and $b$ are:

$$
\begin{aligned}
\hat{Y}_{j, t}+\hat{p}_{j, t}-\hat{p}_{o, t}- & {\left[(1-v)\left(1-\Psi_{k}\right)\left(O_{j} / Y_{j}\right)^{1-v}+v\right] \hat{O}_{j, t} } \\
- & {\left[(1-v) \Psi_{k}\left(K_{j} / Y_{j}\right)^{1-v}\right] \hat{K}_{j, t}=\hat{z}_{k o, j, t} }
\end{aligned}
$$


where $\hat{z}_{k o, j, t}$ is the wedge between the marginal product of oil and the relative price of oil in country $j$. Output of country $\mathrm{j}$ is given by

$$
\begin{aligned}
\hat{Y}_{j, t}-\alpha \hat{N}_{j, t}-(1-\alpha)\left(1-\Psi_{k}\right)\left(O_{j} / Y_{j}\right)^{1-v} \hat{O}_{j, t} & \\
& -(1-\alpha) \Psi_{k}\left(K_{j} / Y_{j}\right)^{1-v} \hat{K}_{j, t}-\hat{z}_{j, t}=0, j=a, b
\end{aligned}
$$

The linearized FOCs for $A_{i, j, t}$ and $B_{i, j, t}, j=a, b$

$$
\begin{aligned}
& \left(\varsigma_{I}+\mu\right) \hat{I}_{j, t}-\mu \hat{A}_{i, j, t}-\hat{p}_{a, t}=\varsigma_{I} \hat{K}_{j, t}-\hat{p}_{k, j, t}, j=a, b \\
& \left(\varsigma_{I}+\mu\right) \hat{I}_{j, t}-\mu \hat{B}_{i, j, t}-\hat{p}_{b, t}=\varsigma_{I} \hat{K}_{j, t}-\hat{p}_{k, j, t}, j=a, b,
\end{aligned}
$$

where $\varsigma_{I}=\left(\Phi^{\prime \prime} / \Phi^{\prime}\right)\left(I_{j} / K_{j}\right)$, and $\hat{p}_{k, j, t}$ is the (shadow) price of installed capital in country $\mathrm{j}$.

Also,

$$
\hat{I}_{j, t}-s_{a, j} \hat{A}_{i, j, t}-\left(1-s_{a, j}\right) \hat{B}_{i, j, t}=0, j=a, b .
$$

The log linearized capital accumulation equation is given by:

$$
\hat{K}_{j, t+1}=(1-\delta) \hat{K}_{j, t}+\delta \hat{I}_{j, t}+\hat{z}_{k, j, t}, j=a, b
$$

where $\hat{z}_{k, j, t}$ is capital accumulation shock (or alternatively investment demand shock).

The linearized FOCs for capital are:

$$
\begin{aligned}
\beta\left[\delta \varsigma_{I}\right. & \left.-\frac{p_{j}}{p_{k, j}} f_{k, j}\left(v+(1-v) \Psi_{k}\left(K_{j} / Y_{j}\right)^{1-v}\right)\right] \hat{K}_{j, t+1}+\left(1-\beta \frac{p_{j}}{p_{k, j}} f_{k, j}\right) \hat{p}_{k, j, t+1} \\
& -\hat{p}_{k, j, t}+\beta \frac{p_{j}}{p_{k, j}} f_{k, j}\left(\hat{p}_{j, t+1}+\hat{y}_{j, t+1}\right)-\beta \delta \varsigma_{I} \hat{I}_{j, t+1} \\
& \left.-\beta \frac{p_{j}}{p_{k, j}} f_{k, j}(1-v)\left(1-\Psi_{k}\right)\left(O_{j} / Y_{j}\right)^{1-v}\right] \hat{O}_{j, t+1}=0, \quad j=a, b
\end{aligned}
$$

where $f_{k}=(1-\alpha) \frac{Y_{j}}{\left[\Psi_{k} K_{j}^{1-v}+\left(1-\Psi_{k}\right) O_{j}^{1-v}\right]}$. 
The oil-producing country, o

The linearized FOCs for consumption:

From the FOC with respect to $A_{c, o, t}$ :

$(\mu-\sigma) \hat{C}_{o, t}-\mu \hat{A}_{c, o, t}-\hat{p}_{a, t}=0$.

Similarly, from the FOC with respect to $B_{c, o, t}$ :

$(\mu-\sigma) \hat{C}_{o, t}-\mu \hat{B}_{c, o, t}-\hat{p}_{b, t}=0$.

Also,

$\hat{C}_{o, t}-s_{a, o} \hat{A}_{c, o, t}-\left(1-s_{a, o}\right) \hat{B}_{c, o, t}=0$,

where $s_{a, o}=\Psi_{o}\left(A_{c, o} / C_{o}\right)^{1-\mu}$ is the steady state expenditure on good a.

Linearized FOC for labor in oil production:

$$
\begin{gathered}
-\left[\xi_{L L} N_{o} /\left(1-N_{o}-N_{x}\right)+\eta_{n n}^{o}\right] \hat{N}_{o, t}-\xi_{L L} N_{x} /\left(1-N_{o}-N_{x}\right) \hat{N}_{x, t}-\eta_{n x}^{o} \hat{X}_{t} \\
-\frac{1}{1-p_{x} / p_{o}} \hat{p}_{o, t}+\frac{1}{p_{o} / p_{x}-1} \hat{p}_{x, t}-\hat{z}_{o, t}=0,
\end{gathered}
$$

where $\xi_{L L}$ is the elasticity of the marginal utility of leisure with respect to leisure, $\eta_{n n}^{o}$ is the elasticity of the marginal product of labor in the production of oil with respect to labor, $\eta_{n x}^{o}$ is the elasticity of the marginal product of labor in the production of oil with respect to reserves, and $p_{x, t}$ is the (shadow) price of reserves. Linearized FOC for labor in production of reserves:

$$
\begin{aligned}
& -\left[\xi_{L L} N_{x} /\left(1-N_{o}-N_{x}\right)+\eta_{n n}^{x}\right] \hat{N}_{x, t}-\xi_{L L} N_{o} /\left(1-N_{o}-N_{x}\right) \hat{N}_{o, t}-\eta_{n i}^{x} \hat{I}_{x, t} \\
& \quad-\hat{p}_{x, t}-\hat{z}_{x, t}=0
\end{aligned}
$$

where $\xi_{n n}^{x}$ is the elasticity of the marginal product of labor in the production of reserves with respect to labor, $\eta_{n i}^{x}$ is the elasticity of the marginal product of labor in the production of reserves 
with respect to reserve investment, and $p_{x, t}$ is the (shadow) price of reserves. Oil output is given by

$\hat{Y}_{o, t}-\Psi_{x}\left(X / Y_{o}\right)^{1-\rho_{o}} \hat{X}_{t}-\left(1-\Psi_{x}\right)\left(N_{o} / Y_{o}\right)^{1-\rho_{o}} \hat{N}_{o, t}-\hat{z}_{o, t}=0$.

The linearized FOCs for $A_{i, o, t}$ and $B_{i, o, t}$,

$\left(\eta_{i i}^{x}+\mu\right) \hat{I}_{x, t}-\mu \hat{A}_{i, o, t}-\hat{p}_{a, t}+\eta_{i n}^{x} \hat{N}_{x, t}=\frac{\Psi_{g}{ }^{\prime \prime}}{\Psi_{g}{ }^{\prime}} \frac{G}{X} \hat{X}_{t}-\left(1+\frac{\Psi_{g}{ }^{\prime \prime}}{\Psi_{g}{ }^{\prime}} \frac{G}{X}\right) \hat{z}_{x, t}-\hat{p}_{x, t}$,

$\left(\eta_{i i}^{x}+\mu\right) \hat{I}_{x, t}-\mu \hat{B}_{i, o, t}-\hat{p}_{b, t}+\eta_{i n}^{x} \hat{N}_{x, t}=\frac{\Psi_{g}{ }^{\prime \prime}}{\Psi_{g}{ }^{\prime}} \frac{G}{X} \hat{X}_{t}-\left(1+\frac{\Psi_{g}{ }^{\prime \prime}}{\Psi_{g}{ }^{\prime}} \frac{G}{X}\right) \hat{z}_{x, t}-\hat{p}_{x, t}$,

where $\eta_{i i}^{x}=\frac{G_{i i} I_{x}}{G_{i}}+\frac{\Psi_{g}{ }^{\prime \prime}}{\Psi_{g}{ }^{\prime}} \frac{G}{X} \Psi_{g}\left(I_{x} / G\right)^{1-\rho_{x}}$ is the elasticity of the marginal production of investment in the production of reserves with respect to investment expenditures while $\eta_{i n}^{x}=\frac{G_{i n} N_{x}}{G_{i}}+\frac{\Psi_{g}{ }^{\prime \prime}}{\Psi_{g}{ }^{\prime}} \frac{G}{X}\left(1-\Psi_{g}\right)\left(N_{x} / G\right)^{1-\rho_{x}}$ is the elasticity of the marginal production of investment in the production of reserves with respect to labor. Goods expenditures on reserves are

$\hat{I}_{x, t}-s_{a, j} \hat{A}_{i, o, t}-\left(1-s_{a, j}\right) \hat{B}_{i, o, t}=0$.

The log-inearized evolution of reserves is given by:

$\hat{X}_{t+1}=\hat{X}_{t}+\frac{G}{X}\left(\Psi_{g}\left(I_{x} / G\right)^{1-\rho_{x}} \hat{I}_{x, t}-\left(1-\Psi_{g}\right)\left(N_{x} / G\right)^{1-\rho_{x}} \hat{N}_{x, t}+\hat{z}_{x, t}\right)-\frac{Y_{o}}{X} \hat{Y}_{o, t}$,

where $G=Y_{o}$ in the steady state. The linearized FOC for reserves is: 


$$
\begin{aligned}
& {\left[(1-\beta) \eta_{x x}^{o}+\beta \frac{G}{X}\left(\frac{\Psi_{g}^{\prime \prime}}{\Psi_{g}^{\prime}} \frac{G}{X}\right)\right] \underset{t}{E} \hat{X}_{t+1}+\beta\left(1-f_{x, o}\right) \underset{t}{E} \hat{p}_{x, t+1}-\hat{p}_{x, t}} \\
& +\left(1-\beta\left(1-f_{x, o}\right)\right) \underset{t}{E} \hat{p}_{o, t+1}+(1-\beta) \eta_{x n}^{0} \underset{t}{E} \hat{N}_{o, t+1} \\
& -\left[\beta \frac{G}{X}\left(\frac{\Psi_{g}^{\prime \prime}}{\Psi_{g}^{\prime}} \frac{G}{X}\right) \Psi_{g}\left(I_{x} / G\right)^{1-\rho_{x}}\right] \underset{t}{E} \hat{I}_{x, t+1} \\
& -\left[\beta \frac{G}{X}\left(\frac{\Psi_{g}^{\prime \prime}}{\Psi_{g}^{\prime}} \frac{G}{X}\right)\left(1-\Psi_{g}\right)\left(N_{x} / G\right)^{1-\rho_{x}}\right] \underset{t}{E} \hat{N}_{x, t+1}-\left[\beta \frac{G}{X}\left(\frac{\Psi_{g}^{\prime \prime}}{\Psi_{g}^{\prime}} \frac{G}{X}\right)\right]_{t}^{E} \hat{z}_{x, t+1} \\
& +(1-\beta) \underset{t}{E} \hat{z}_{o, t+1}=0,
\end{aligned}
$$

where $f_{x, o}=\frac{(1-\beta)}{\beta\left(\frac{p_{o}}{p_{x}}-1\right)}$.

Finally, the resource constraints imply:

$$
\begin{aligned}
& \hat{Y}_{a, t}=\frac{A_{c, a}}{Y_{a}} \hat{A}_{c, a, t}+\frac{A_{c, b}}{Y_{a}} \hat{A}_{c, b, t}+\frac{A_{c, o}}{Y_{a}} \hat{A}_{c, o, t}+\frac{A_{i, a}}{Y_{a}} \hat{A}_{i, a, t}+\frac{A_{i, b}}{Y_{a}} \hat{A}_{i, b, t}+\frac{A_{i, o}}{Y_{a}} \hat{A}_{i, o, t} \\
& \hat{Y}_{b, t}=\frac{B_{c, a}}{Y_{b}} \hat{B}_{c, a, t}+\frac{B_{c, b}}{Y_{b}} \hat{B}_{c, b, t}+\frac{B_{c, o}}{Y_{b}} \hat{B}_{c, o, t}+\frac{B_{i, a}}{Y_{b}} \hat{B}_{i, a, t}+\frac{B_{i, b}}{Y_{b}} \hat{B}_{i, b, t}+\frac{B_{i, o}}{Y_{b}} \hat{B}_{i, o, t} \\
& \hat{Y}_{o, t}=\frac{O_{a}}{Y_{o}} \hat{O}_{a, t}+\frac{O_{b}}{Y_{o}} \hat{O}_{b, t}
\end{aligned}
$$

\section{B. Observation Equations in the State Space Model}

Our data consists of observations on US GDP, consumption, investment, and employment, the relative (non oil) import price for the US, US oil consumption (barrels), real oil price (deflated by US GDP deflator), world oil production (barrels), ROW real GDP (PPP, in dollars), and ROW real investment (PPP, in dollars). For several variables the mapping between the model and the data are exact: $\hat{Y}_{u s, t}^{\text {cons }}=\hat{C}_{a, t}, \hat{Y}_{u s, t}^{i v v}=\hat{I}_{a, t}, \hat{Y}_{R O W, t}^{i v v}=\hat{I}_{a, t} \hat{Y}_{u s, t}^{e m p}=\hat{N}_{a, t}$, 
$\hat{Y}_{\text {oil output }, t}=\hat{Y}_{o, t}$, and $\hat{Y}_{u s, t}^{\text {oil cons }}=\hat{O}_{a, t}$. However, several variables need to be transformed to correspond to the data we will employ. Output in the model corresponds to gross output rather than value added, thus GDP is given by $\hat{Y}_{\text {row }, t}^{g d p}=\left(\hat{Y}_{b, t}-\frac{P_{o} O_{a}}{P_{a} Y_{a}} \hat{O}_{a, t}\right) /\left(1-\frac{P_{o} O_{a}}{P_{a} Y_{a}}\right)$ and $\hat{Y}_{u s, t}^{g d p}=\left(\hat{Y}_{a, t}-\frac{P_{o} O_{a}}{P_{a} Y_{a}} \hat{O}_{a, t}\right) /\left(1-\frac{P_{o} O_{a}}{P_{a} Y_{a}}\right)$. Similarly, as the GDP (value added) deflator was used to deflate the import price and oil price: $\hat{Y}_{u s, t}^{\text {relimport price }}=\left(\hat{P}_{b, t}-\hat{P}_{a, t}\right)+\left(\hat{P}_{o, t}-\hat{P}_{a, t}\right) \frac{\frac{P_{o} O_{a}}{P_{a} Y_{a}}}{1-\frac{P_{o} O_{a}}{P_{a} Y_{a}}}$, and $\hat{Y}_{\text {real oil price,t }}=\left(\hat{P}_{o, t}-\hat{P}_{a, t}\right) /\left(1-\frac{P_{o} O_{a}}{P_{a} Y_{a}}\right)$.

\section{Bayesian Estimation of the DSGE Model}

One can write the solution to the linearized, rational expectations DSGE model in terms of a state space model:

$$
\begin{aligned}
& Y_{t}^{\text {mod el }}=\Pi S_{t}^{\text {mod el }} \\
& S_{t}=M S_{t-1}+V_{t}^{\text {mod el }} .
\end{aligned}
$$

$Y_{t}^{\text {mod el }}$ is a vector of endogenous variables in the model. $S_{t}^{\text {model }}$ is the state vector which includes the capital stocks of US (country a) and ROW (country b) and oil reserves as well as the ten exogenous shock variables: TFP, labor wedge, oil wedge, investment (capital accumulation) shocks for countries $\mathrm{a}$ and $\mathrm{b}$ and oil production and oil reserve shocks.

The model is written in terms of quarters while we have only annual data for ROW GDP and ROW investment. Thus, we partition the observation equation of the state space model into 
two sets of equations - one corresponding to quarterly observations, the other corresponding to annual observations. The observation equation is given by:

$$
Y_{t}^{\text {obs }}=\left(\begin{array}{c}
Y_{t}^{\text {quarterly }} \\
Y_{t}^{\text {annual }}
\end{array}\right)=\left(\begin{array}{cccc}
\Pi_{1} & 0 & 0 & 0 \\
.25 \Pi_{2} & .25 \Pi_{2} & .25 \Pi_{2} & .25 \Pi_{2}
\end{array}\right)\left(\begin{array}{l}
S_{t}^{\text {mod el }} \\
S_{t-1}^{\text {mod el }} \\
S_{t-2}^{\text {mod el }} \\
S_{t-3}^{\text {mod el }}
\end{array}\right) .
$$

The corresponding state equation is given by:

$$
\left(\begin{array}{l}
S_{t}^{\text {mod el }} \\
S_{t-1}^{\text {mod el }} \\
S_{t-2}^{\text {mod el }} \\
S_{t-3}^{\text {model }}
\end{array}\right)=\left(\begin{array}{cccc}
M & 0 & 0 & 0 \\
I & 0 & 0 & 0 \\
0 & I & 0 & 0 \\
0 & 0 & I & 0
\end{array}\right)\left(\begin{array}{l}
S_{t-1}^{\text {mod el }} \\
S_{t-2}^{\text {mod el }} \\
S_{t-3}^{\text {mod el }} \\
S_{t-4}^{\text {mod el }}
\end{array}\right)+\left(\begin{array}{c}
V_{t}^{\text {mod el }} \\
0 \\
0 \\
0
\end{array}\right) \text {. }
$$

The empirical state space model implied by (C3) and (C4) can be rewritten as:

$$
\begin{aligned}
& Y_{t}^{o b s}=H(\theta) S_{t}+W_{t}, W_{t} \sim \operatorname{MVN}(0, R) \\
& S_{t}=F(\theta) S_{t-1}+V_{t}, V_{t} \sim \operatorname{MVN}(0, Q(\theta)) .
\end{aligned}
$$

$Y_{t}^{o b s}$ is the vector of observable time series, $S_{t}$ is the vector of unobserved state variables, and $\theta$ is the vector of structural parameters in the DSGE model. In our application, $Y_{t}^{\text {obs }}$ contains detrended quarterly per capita real U.S. GDP, detrended quarterly per capita real U.S. consumption, detrended quarterly per capita real U.S. investment, detrended per captia quarterly U.S. oil consumption, detrended quarterly world oil production, demeaned quarterly real oil price, detrended quarterly real non-oil import price for the U.S, detrended annual real GDP for ROW (PPP constant US dollars), and detrended annual real investment expenditures for ROW (PPP constant US dollars). We scale up all the variables by 100 . We set $R$ to be a diagonal matrix with diagonal elements equal to $10^{-4}$. We treat observations for the annual data as missing for all but the fourth quarter of the year. 
Given the parameters, $\theta$, we can estimate the unobserved states by the Kalman Filter.

The predictive log likelihood of the state space model is given by:

$$
\begin{aligned}
l\left(\mathbf{Y}_{T}, \theta\right) & =\sum_{t=1}^{T}\left\{-.5 \log \left(\operatorname{det}\left(H(\theta)^{\prime} P_{t \mid t-1} H(\theta)+R\right)\right)\right. \\
& \left.-.5\left(Y_{t}-H(\theta) S_{t \mid t-1}\right)^{\prime}\left(H(\theta)^{\prime} P_{t \mid t-1} H(\theta)+R\right)^{-1}\left(Y_{t}-H(\theta) S_{t \mid t-1}\right)\right\}
\end{aligned}
$$

where $S_{t \mid t-1}$ and $P_{t \mid t-1}$ is the conditional mean and variance of $\mathrm{S}_{\mathrm{t}}$ from the Kalman filter.

Given a prior distribution over parameters, $h(\theta)$, the posterior distribution, $P\left(\theta \mid \mathbf{Y}_{\mathrm{T}}\right)$, is

$$
P\left(\theta \mid \mathbf{Y}_{\mathbf{T}}\right) \propto \exp \left(l\left(\mathbf{Y}_{\mathbf{T}}, \theta\right)\right) h(\theta) .
$$

Because the log-likelihood is a highly nonlinear function of the structural parameter vector, it is not possible to write an analytical expression for the posterior distribution. As a result, we use Bayesian Markov Chain Monte Carlo methods to estimate the posterior distribution of the parameter vector, $\theta$. In particular, we employ a Metropolis-Hasting sampler to generate draws from the posterior distributions. The algorithm is as follows:

(i) Given a previous draw of the parameter vector, $\theta^{(i-1)}$, draw a candidate vector $\theta^{c}$ from the distribution $g\left(\theta \mid \theta^{(i-1)}\right)$.

(ii) Determine the acceptance probability for the candidate draw, $\alpha\left(\theta^{c}, \theta^{(i-1)}\right)=\min \left[\frac{\exp \left(l\left(\mathbf{Y}_{\mathbf{T}}, \theta^{(c)}\right)\right) h\left(\theta^{(c)}\right)}{\exp \left(l\left(\mathbf{Y}_{\mathbf{T}}, \theta^{(i-1)}\right)\right) h\left(\theta^{(i-1)}\right)} \frac{g\left(\theta^{(i-1)} \mid \theta^{c}\right)}{g\left(\theta^{c} \mid \theta^{(i-1)}\right)}, 1\right]$.

(iii) Determine a new draw from the posterior distribution, $\theta^{(i)}$.

$\theta^{(i)}=\theta^{c}$ with probability $\alpha\left(\theta^{c}, \theta^{(i-1)}\right)$

$\theta^{(i)}=\theta^{(i-1)}$ with probability $1-\alpha\left(\theta^{c}, \theta^{(i-1)}\right)$.

(iv) Return to (i). 
Starting from an initial parameter vector and repeating enough times, the distribution parameters draws, $\theta^{(i)}$, will converge to the true posterior distribution.

In our application, $\theta^{c}=\theta^{(i-1)}+v$ where $v$ is drawn from a multivariate t-distribution with five degrees of freedom and a covariance matrix $\Sigma$. We set $\Sigma$ to be a scaled value of the Hessian matrix of $\left.-1\left(\boldsymbol{Y}_{T}, \theta\right)\right)-\ln (\mathrm{h}(\theta))$ evaluated at the posterior mode. We choose the scaling so that around $20 \%-30 \%$ of the candidate draws are accepted. We run the sampler 105,000 times, keeping the last 5,000 draws to estimate the posterior distribution. We also obtain the posterior distributions for the unobserved states. Given a parameter draw, we draw from the conditional posterior distribution for the unobserved states, $\mathrm{P}\left(\boldsymbol{S}_{T} \mid \Theta^{(\mathrm{i})}, \boldsymbol{Y}_{T}\right)$. Here we use the "filter forward, sample backwards" approach proposed by Carter and Kohn (1994) and discussed in Kim and Nelson (1999b).

\section{Data Sources for Rest of World (Oil-Consuming Country)}

In order to obtain an approximate estimate of the data for the rest of world oil-consuming country, we aggregate data from 29 countries-Brazil, China, and India, plus 26 of the 30 OECD countries. We exclude the United States, whose data is used for the Home Country in the model; Mexico, which is a major oil-producing country, and the Czech Republic and Slovakia, neither of which have reliable data prior to 1990. Because real GDP and investment are reported in U.S. dollars, we aggregate these series across countries. We convert ROW GDP and investment to per capita series by dividing with population aggregated across countries.

For the period 1970 to 2003, the data for population, real GDP, and real investment for all 29 countries are taken from the Penn World Table. For the period 2004 through 2006, the data for the 26 OECD countries are from the OECD; and the data for Brazil, India and China are 
from Haver Analytics. The data from 2004 to 2006 were spliced to the earlier data in 2003, country by country, and then aggregated to obtain per capita measures of ROW output and investment. 


\section{References:}

Alquist, Ron and Lutz Kilian (2007), "What Do We Learn from the Price of Crude Oil Futures?" CEPR Discussion Papers 6548, University of Michigan.

Backus, David K. and Mario J. Crucini (2000), "Oil Prices and the Terms of Trade," Journal of International Economics 50: 185-213.

Backus, David K., Patrick J. Kehoe and Finn E. Kydland (1992), "International Real Business Cycles," Journal of Political Economy 100(4): 745-75.

Backus, David K., Patrick J. Kehoe and Finn E. Kydland, (1994), "Dynamics of the Trade Balance and the Terms of Trade: the J-curve?" American Economic Review 84(1): 84103.

Balke, Nathan S., Stephen P. Brown and Mine K. Yücel (2002), "Oil Price Shocks and the U.S. Economy: Where Does the Asymmetry Originate?" The Energy Journal 23(3): 27-52 (Third Quarter).

Barsky, Robert, and Lutz Killian (2001), "Do We Really Know that Oil Caused the Great Stagflation? A Monetary Alternative," NBER Macroeconomics Annual 2001, (May): 137-183.

Barsky, Robert, and Lutz Killian (2004), "Oil and the Macroeconomy since the 1970s," Journal of Economic Perspectives, 18(4): 115-134 (Fall).

Bernanke, Ben S. (2004), "The Great Moderation," speech at the meetings of the Eastern Economic Association (February).

Bernanke, Ben S., Mark Gertler, and Mark Watson (1997), "Systematic Monetary Policy and the Effects of Oil Price Shocks," Brookings Papers on Economics Activity 1997(1): 91-142.

Blanchard, Olivier and J. Gali (2007), "The Macroeconomic Effects of Oil Price Shocks: Why are the 2000s so Different from the 1970s?" Massachusetts Institute of Technology, Department of Economics, Working Paper 07-21 (August).

Blanchard, O, and C. Kahn (1980), "The Solution of Linear Difference Equations under Rational Expectations," Econometrica, 48: 1305-1310.

Blanchard, Olivier and John Simon (2001), "The Long and Large Decline in U.S. Output Volatility," Brookings Papers on Economic Activity (1): 135-64.

Bodenstein, Martin, Christopher J. Erceg and Luca Guerrieri (2007), "Oil Shocks and External Adjustment," Board of Governors of the Federal Reserve System, International Finance Discussion Paper Number 897 (June).

Bohi, Douglas R. (1989), Energy Price Shocks and Macroeconomic Performance, Resources for the Future, Washington, D.C.

Bohi, Douglas R. (1991), "On the Macroeconomic Effects of Energy Price Shocks," Resources and Energy 13(2):145-62.

Boivin, Jean and Marc P. Giannoni (2006), "Has Monetary Policy Become More Effective?" Review of Economics and Statistics 88: 445-62 (August).

Brown, Stephen P. A. and Mine K. Yücel (1999), "Oil Prices and U.S. Aggregate Economic Activity: A Question of Neutrality," Economic and Financial Review, Federal Reserve Bank of Dallas (Second Quarter).

Bruno, Michael R. and Jeffrey Sachs (1981), "Supply versus Demand Approaches to the Problem of Stagflation," in Macroeconomic Policies for Growth and Stability, edited by H. Giersch, Tubingen, J. C. B. Mohr. 
Bruno, Michael R. and Jeffrey Sachs (1985), Economics of Worldwide Stagflation. Cambridge, Mass.:Harvard University Press.

Burbidge, J and A. Harrison (1984), "Testing for the Effects of Oil-Price Rises Using Vector Autoregression," International Economic Review, 25:459-484.

Carter, C.K. and P. Kohn (1994), "On Gibbs Sampling for State Space Models,” Biometrica 81, 541-553.

Chari, V.V., Patrick Kehoe, and Ellen McGrattan (2007), "Business Cycle Accounting," Econometrica, 75(3): 781-836.

Darby, Michael R. (1982), "The Price of Oil and World Inflation and Recession," American Economic Review, 72:738-751.

Davis, Steven J. and John Haltiwanger (2001), "Sectoral Job Creation and Destruction Responses to Oil Price Changes and Other Shocks," Journal of Monetary Economics (December).

Elekdag, Sukru and Douglas Laxton (2007), "Understanding the Link Between Oil Prices and the Economy," Box 1.1 in IMF World Economic Outlook.

Ferderer, J. Peter (1996), "Oil Price Volatility and the Macroeconomy: A Solution to the Asymmetry Puzzle," Journal of Macroeconomics 18:1-16.

Geweke, J. (1999), "Using Simulation Methods for Bayesian Econometric Models: Inference, Development, and Communication," Econometric Reviews 18, 1-126.

Gisser, M. and T. H. Goodwin (1986), "Crude Oil and the Macroeconomy: Tests of Some Popular Notions," Journal of Money, Credit and Banking, 18:95-103.

Greenwood, Jeremy and Yorukoglu, Mehmet (1997). “1974,” Carnegie-Rochester Conference Series on Public Policy 46:49-95.

Hall, Robert E. (1997), "Macroeconomic Fluctuations and the Allocation of Time," Journal of Labor Economics, 15(1): S223-S250.

Hamilton, James D. (1983), "Oil and the Macroeconomy since World War II," Journal of Political Economy 91(2): 228-48.

Hamilton, James D. (1996), "This is What Happened to the Oil Price Macroeconomy Relationship," Journal of Monetary Economics 38(2): 215-20 (October).

Hamilton, James D. (2003), "What Is an Oil Shock?” Journal of Econometrics 113: 363-98.

Hamilton, James D. and Ana Maria Herrera (2004), "Oil Shocks and Aggregate Macroeconomic Behavior: The Role of Monetary Policy," Journal of Money, Credit, Banking 36(2), 26586.

Herrera, Ana María and Elena Pesavento (forthcoming), "Oil Price Shocks, Systematic Monetary Policy and the 'Great Moderation'," Macroeconomic Dynamics.

Hickman, Bert, Hillard Huntington and James Sweeney, eds. (1987), Macroeconomic Impacts of Energy Shocks, Amsterdam: North-Holland.

Hooker, Mark A. (1996), "What Happened to the Oil Price Macroeconomy Relationship?" Journal of Monetary Economics, 38(2): 195-213 (October).

Hooker, Mark A. (2002), “Are Oil Shocks Inflationary? Asymmetric and Nonlinear Specifications versus Changes in Regime," Journal of Money, Credit and Banking 34(2): 540-561.

Huntington, Hillard (2003), "Energy Disruptions, Interfirm Price Effects and the Aggregate Economy," Energy Economics 25 (2), 119-136.

Huntington, Hillard G. (2005), Macroeconomic Consequences of Higher Oil Prices, Energy Modeling Forum Special Report 9, Stanford University, Stanford, California, August. 
Jones, Donald W., Paul N. Leiby and Inja K. Paik (2004), “Oil Price Shocks and the Macroeconomy: What Has Been Learned Since 1996?” The Energy Journal, 25 (2).

Kahn, James A., Margaret M. McConnell and Gabriel Perez-Quiros (2002), "On the Causes of the Increased Stability of the U.S. Economy," Economic Policy Review, Federal Reserve Bank of New York (May):183-202.

Kilian, Lutz (2008), "Exogenous Oil Supply Shocks: How Big Are They and How Much Do They Matter for the U.S. Economy?" Review of Economics and Statistics, 90(2): 216-240 (May).

Kilian, Lutz (2007), "Not All Oil Price Shocks Are Alike: Disentangling Demand and Supply Shocks in the Crude Oil Market," Working Paper, University of Michigan.

Kim, Chang-Jin and Charles Nelson (1999a), "Has the U.S. Economy Become More Stable? A Bayesian Approach Based on a Markov-Switching Model of the Business Cycle," Review of Economics and Statistics 81: 608-16 (November).

Kim, Chang-Jin and Charles Nelson (1999b), State Space Models with Regime Switching, MIT Press, Cambridge.

Kim, In-Moo and Prakash Loungani (1992), "The Role of Energy in Real Business Cycle Models, Journal of Monetary Economics 29: 173-189.

King, Robert. G., Charles I. Plosser and Sergio T. Rebelo (1988), "Production, Growth, and Business Cycles: I. The Basic Neoclassical Model, Journal of Monetary Economics 21: 195-232.

Lubik, T. and F. Schorfheide (2004), "Testing for Indeterminacy: An Application to U.S. Monetary Policy," American Economic Review, 94(1): 190-217.

McConnell, Margaret M. and Gabriel Perez-Quiros (2000), "Output Fluctuations in the United States: What Has Changed Since the Early 1980s?" American Economic Review 90: 1464-76 (December)

Mork, Knut Anton and Robert E. Hall (1980), "Energy Prices, Inflation, and Recession, 19741975," The Energy Journal, 1(3):31-63.

Nordhaus, William D. (2004). "Retrospective on the Postwar Productivity Slowdown," Cowles Foundation Discussion Paper \# 1494.

Pierce, James L. and Jared J. Enzler (1974), "The Effects of External Inflationary Shocks," Brookings Papers on Economic Activity, 1:13-61.

Rasche, R.H. and J.A. Tatom (1977), "The Effects of the New Energy Regime on Economic Capacity, Production and Prices," Economic Review, Federal Reserve Bank of St. Louis, 59(4):2-12.

Rotemberg, Julio and Michael Woodford (1996), "Imperfect Competition and the Effects of Energy Price Increases on Economic Activity," Journal of Money, Credit and Banking 28(4): 549-577.

Samaniego, Roberto M. (2006). "Organizational Capital, Technology Adoption and the Productivity Slowdown,” Journal of Monetary Economics, 53:1555-1569.

Segal, Paul (2007), “Why Do Oil Price Shocks No Longer Shock?” Oxford Institute for Energy Studies Working Paper.

Smets, F. and R. Wouters (2007), "Shocks and Frictions in U.S. Business Cycles: A Bayesian DSGE Approach," American Economic Review, 97(3): 586-606.

Stock, James H. and Mark W. Watson (2003), "Has the Business Cycle Changed? Evidence and Explanations," paper presented at the Federal Reserve Bank of Kansas City symposium on Monetary Policy and Uncertainty, Jackson Hole, Wyoming (August). 


\begin{tabular}{|c|c|c|c|c|c|c|c|c|}
\hline \multirow[b]{2}{*}{ Parameter } & \multicolumn{4}{|c|}{ Prior distribution } & \multicolumn{4}{|c|}{ Posterior distribution } \\
\hline & type & mode & $\begin{array}{c}5^{\text {th }} \\
\text { percentile }\end{array}$ & $\begin{array}{c}95^{\text {th }} \\
\text { percentile }\end{array}$ & mode & Mean & $\begin{array}{c}5^{\text {th }} \\
\text { percentile }\end{array}$ & $\begin{array}{c}95^{\text {th }} \\
\text { percentile }\end{array}$ \\
\hline Discount factor $(\beta)$ & Beta & 0.99 & 0.981 & 0.994 & 0.990 & 0.991 & 0.988 & 0.993 \\
\hline $\begin{array}{l}\text { Intertemporal elasticity of substitution } \\
(1 / \sigma)\end{array}$ & Gamma & 0.5 & 0.218 & 1.052 & 0.344 & 0.369 & 0.249 & 0.598 \\
\hline $\begin{array}{l}\text { Elast. of subst. home and foreign goods } \\
\qquad(1 / \mu)\end{array}$ & Gamma & 1.5 & 0.238 & 4.329 & 0.341 & 0.335 & 0.228 & 0.472 \\
\hline $\begin{array}{c}\text { Share of foreign goods in invest. and } \\
\text { cons. }\end{array}$ & Beta & 0.15 & 0.116 & 0.193 & 0.094 & 0.090 & 0.072 & 0.106 \\
\hline Labor's share in time & Beta & 0.3 & 0.241 & 0.367 & 0.291 & 0.290 & 0.248 & 0.336 \\
\hline Labor's share GDP $(\alpha)$ & Beta & 0.64 & 0.600 & 0.677 & 0.597 & 0.601 & 0.568 & 0.634 \\
\hline Depreciation rate on capital $(\delta)$ & Beta & 0.025 & 0.019 & 0.033 & 0.017 & 0.016 & 0.012 & 0.019 \\
\hline Capital adjustment cost & Gamma & 0.05 & 0.026 & 0.99 & 0.187 & 0.215 & 0.139 & 0.296 \\
\hline $\begin{array}{l}\text { Elasticity of marginal utility of leisure in } \\
\text { oil country }(x-1)\end{array}$ & Gamma & 2 & 0.692 & 12.578 & 7.951 & 7.324 & 3.881 & 12.819 \\
\hline Elast. of subst. oil and capital & Gamma & 0.09 & 0.035 & 1.066 & 0.104 & 0.105 & 0.087 & 0.124 \\
\hline Energy expenditure relative to GDP & Beta & 0.1 & 0.072 & 0.139 & 0.058 & 0.057 & 0.048 & 0.066 \\
\hline Labor share in oil country GDP & Beta & 0.5 & 0.272 & 0.795 & 0.488 & 0.447 & 0.287 & 0.642 \\
\hline$p_{o} / p_{x}$ & Gamma* & 6 & 3.044 & 16.739 & 5.703 & 5.732 & 3.988 & 8.218 \\
\hline$Y_{o} / X$ & Beta & 0.0065 & 0.0044 & 0.0098 & 0.0052 & 0.0045 & 0.0031 & 0.0067 \\
\hline Elasticity of subst. in oil production & Gamma & 1 & 0.409 & 3.148 & 1.357 & 1.664 & 0.566 & 3.639 \\
\hline Elasticity of subst. in reserve prod. & Gamma & 1 & 0.409 & 3.148 & 0.830 & 0.813 & 0.180 & 1.796 \\
\hline Reserve adjustment cost & Gamma & 0.05 & 0.026 & 0.99 & 0.046 & 0.059 & 0.026 & 0.187 \\
\hline
\end{tabular}

\footnotetext{
* The prior distribution for $p_{o} / p_{x}-1$ is a gamma distribution.
} 


\begin{tabular}{|c|c|c|c|c|c|c|c|c|}
\hline & \multicolumn{4}{|c|}{ Prior distribution } & \multicolumn{4}{|c|}{ Posterior distribution } \\
\hline$A R(1)$ coefficient & type & mode & $\begin{array}{c}5^{\text {th }} \\
\text { percentile }\end{array}$ & $\begin{array}{c}95^{\text {th }} \\
\text { percentile }\end{array}$ & mode & Mean & $\begin{array}{c}5^{\text {th }} \\
\text { percentile }\end{array}$ & $\begin{array}{c}95^{\text {th }} \\
\text { percentile }\end{array}$ \\
\hline US total factor productivity & Beta & 0.70 & 0.112 & 0.942 & 0.847 & 0.872 & 0.806 & 0.931 \\
\hline ROW total factor productivity & Beta & 0.70 & 0.112 & 0.942 & 0.981 & 0.983 & 0.972 & 0.990 \\
\hline Spillover in total factor productivity & Normal & 0.088 & 0.006 & 0.170 & 0.029 & 0.022 & 0.006 & 0.039 \\
\hline Oil production shock & Beta & 0.70 & 0.112 & 0.942 & 0.890 & 0.903 & 0.867 & 0.932 \\
\hline Oil reserve shock & Beta & 0.70 & 0.112 & 0.942 & 0.980 & 0.978 & 0.956 & 0.994 \\
\hline US labor wedge & Beta & 0.70 & 0.112 & 0.942 & 0.998 & 0.998 & 0.993 & 0.999 \\
\hline ROW labor wedge & Beta & 0.70 & 0.112 & 0.942 & 0.994 & 0.996 & 0.989 & 0.999 \\
\hline US oil wedge & Beta & 0.70 & 0.112 & 0.942 & 0.891 & 0.906 & 0.879 & 0.933 \\
\hline ROW oil wedge & Beta & 0.70 & 0.112 & 0.942 & 0.732 & 0.750 & 0.654 & 0.831 \\
\hline US investment shock & Beta & 0.70 & 0.112 & 0.942 & 0.874 & 0.876 & 0.767 & 0.960 \\
\hline ROW investment shock & Beta & 0.70 & 0.112 & 0.942 & 0.989 & 0.994 & 0.982 & 0.999 \\
\hline \multicolumn{9}{|l|}{ Standard deviation of innovations } \\
\hline US total factor productivity & Gamma & 0.10 & 0.172 & 9.180 & 0.518 & 0.529 & 0.527 & 0.589 \\
\hline ROW total factor productivity & Gamma & 0.10 & 0.172 & 9.180 & 0.981 & 0.969 & 0.830 & 1.140 \\
\hline Corr(US TFP, ROW TFP) & Beta $^{\dagger}$ & 0.258 & -0.240 & 0.630 & 0.427 & 0.421 & 0.273 & 0.553 \\
\hline Oil production shock & Gamma & 0.10 & 0.172 & 9.180 & 2.937 & 3.019 & 2.394 & 3.595 \\
\hline Oil reserve shock & Gamma & 0.10 & 0.172 & 9.180 & 2.995 & 3.632 & 1.845 & 5.362 \\
\hline US labor wedge & Gamma & 0.10 & 0.172 & 9.180 & 0.882 & 0.881 & 0.785 & 0.976 \\
\hline ROW labor wedge & Gamma & 0.10 & 0.172 & 9.180 & 2.238 & 2.159 & 1.839 & 2.470 \\
\hline US oil wedge & Gamma & 0.10 & 0.172 & 9.180 & 16.665 & 16.743 & 14.486 & 19.311 \\
\hline ROW oil wedge & Gamma & 0.10 & 0.172 & 9.180 & 33.435 & 34.212 & 28.699 & 40.243 \\
\hline US investment shock & Gamma & 0.10 & 0.172 & 9.180 & 0.154 & 0.158 & 0.075 & 0.257 \\
\hline ROW investment shock & Gamma & 0.10 & 0.172 & 9.180 & 0.037 & 0.030 & 0.021 & 0.041 \\
\hline
\end{tabular}

\footnotetext{
${ }^{\dagger}$ The prior distribution for (Corr(US TFP,ROW TFP)+1)/2 is a beta distribution.
} 
Table 3. Model comparison

\begin{tabular}{|c|c|c|}
\hline & Log marginal likelihood & $\begin{array}{c}\text { Bayes factor relative to } \\
\text { benchmark model }\end{array}$ \\
\hline Benchmark model & -1528.1 & 1.0 \\
\hline Backus-Crucini parameters & -1842.3 & $\exp (314.2)$ \\
\hline State space VAR(1) & -2108.6 & $\exp (580.5)$ \\
\hline
\end{tabular}

Ratio of marginal likelihood of benchmark model to alternative model. 
Figure 1

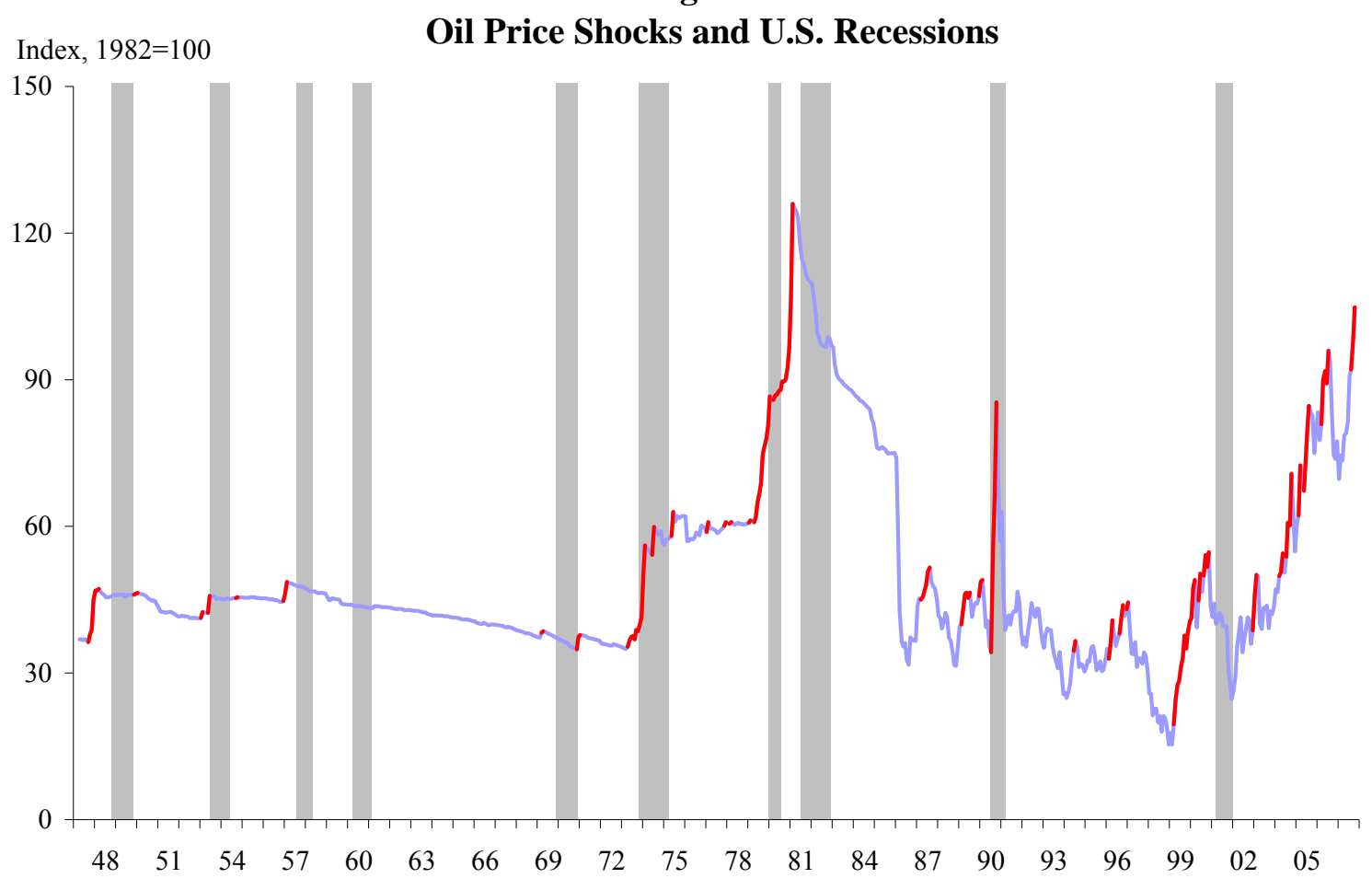




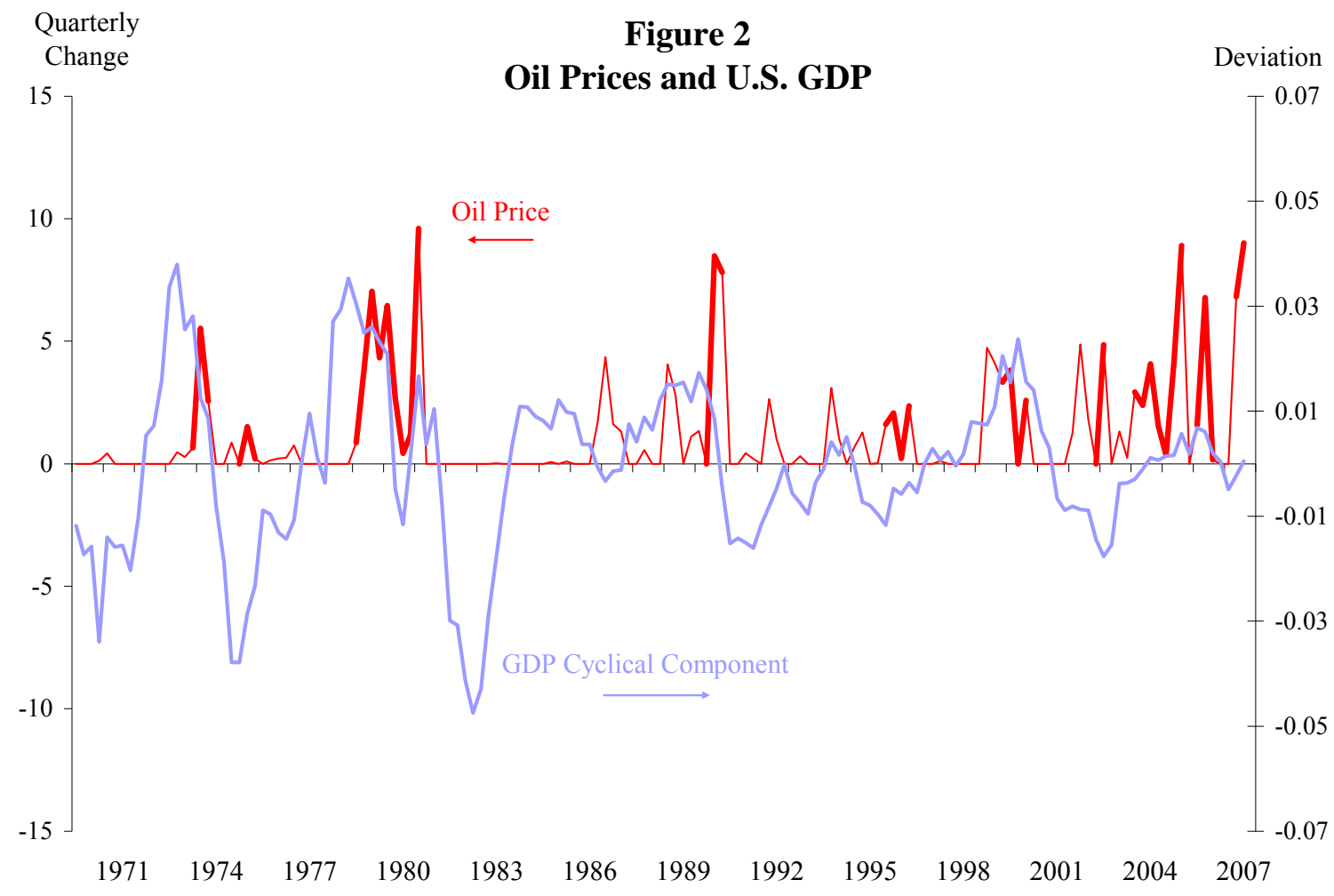


Figure 3A. Impulse Responses of Oil Price and Oil Output
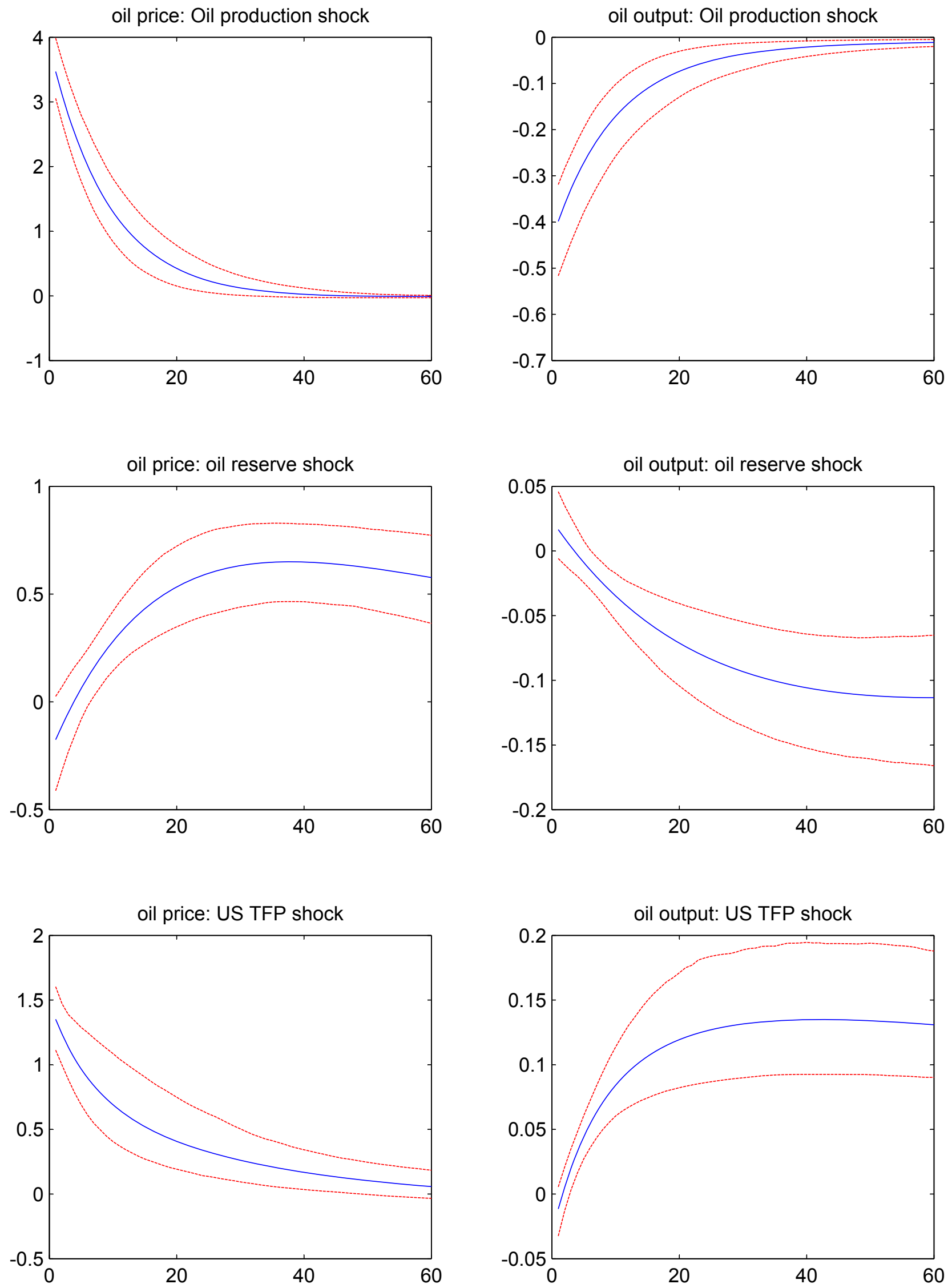
Figure 3B. Impulse Responses of Oil Price and Oil Output
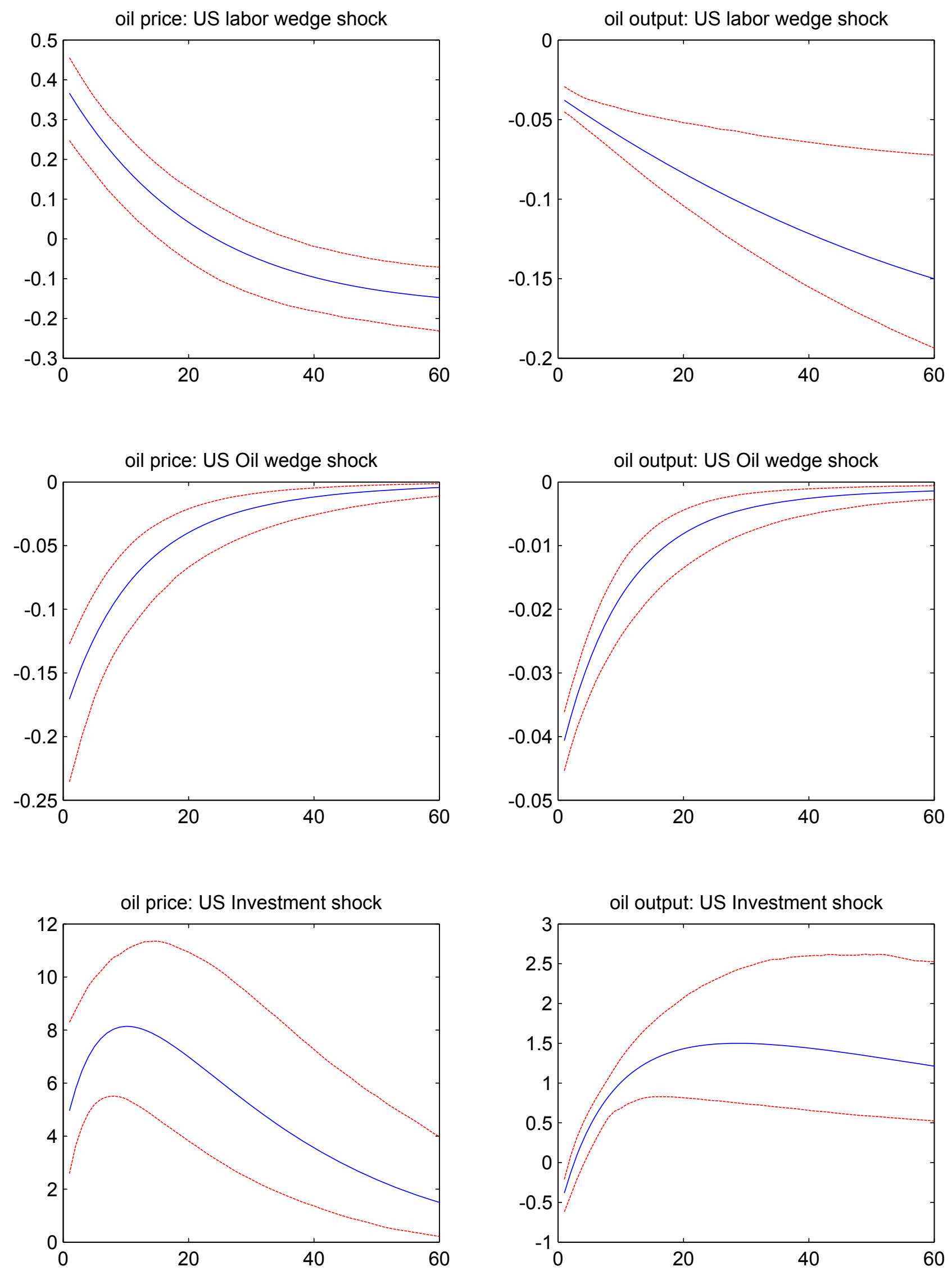
Figure 4A. Impulse Response of U.S. Real GDP
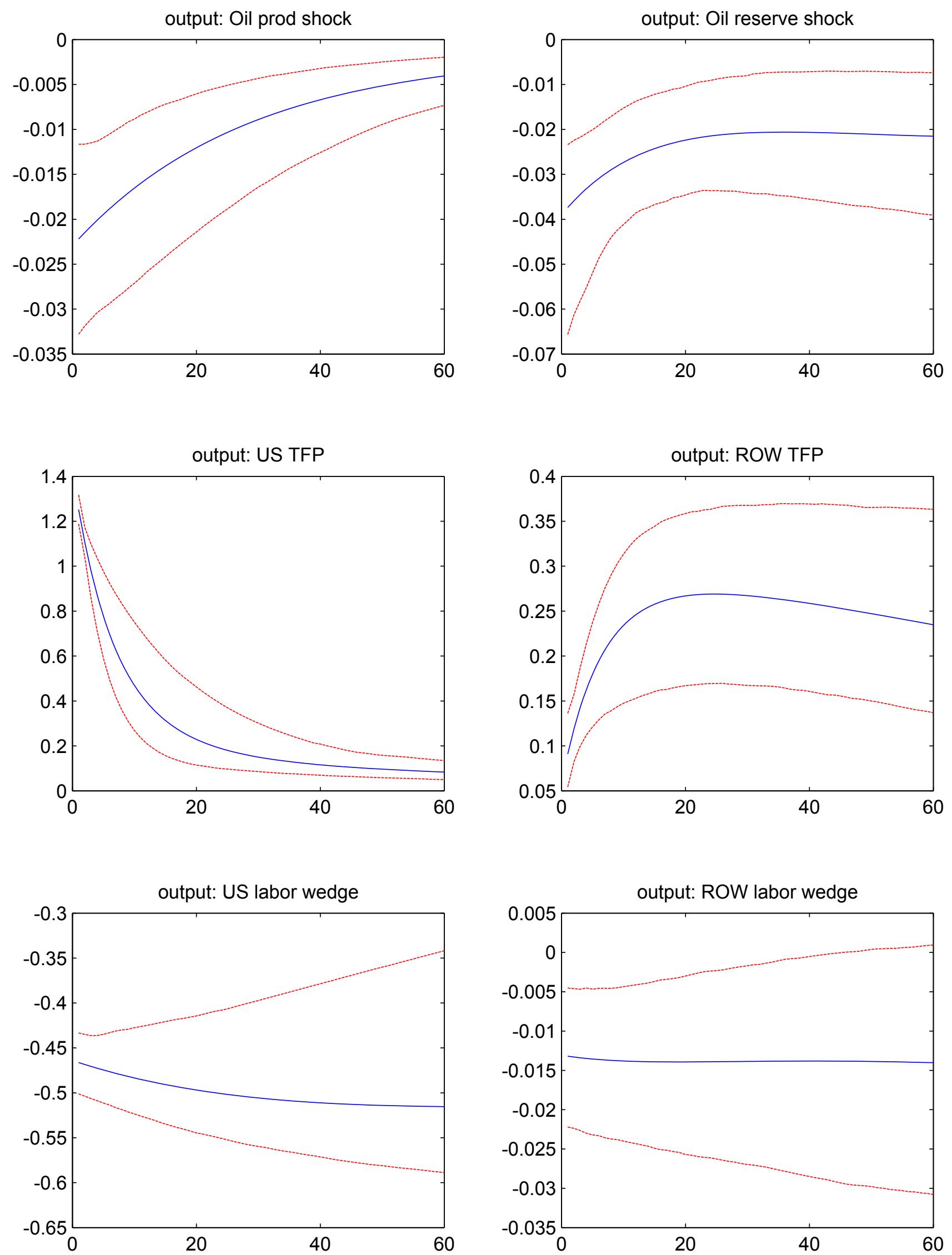
Figure 4B. Impulse Response of U.S. Real GDP
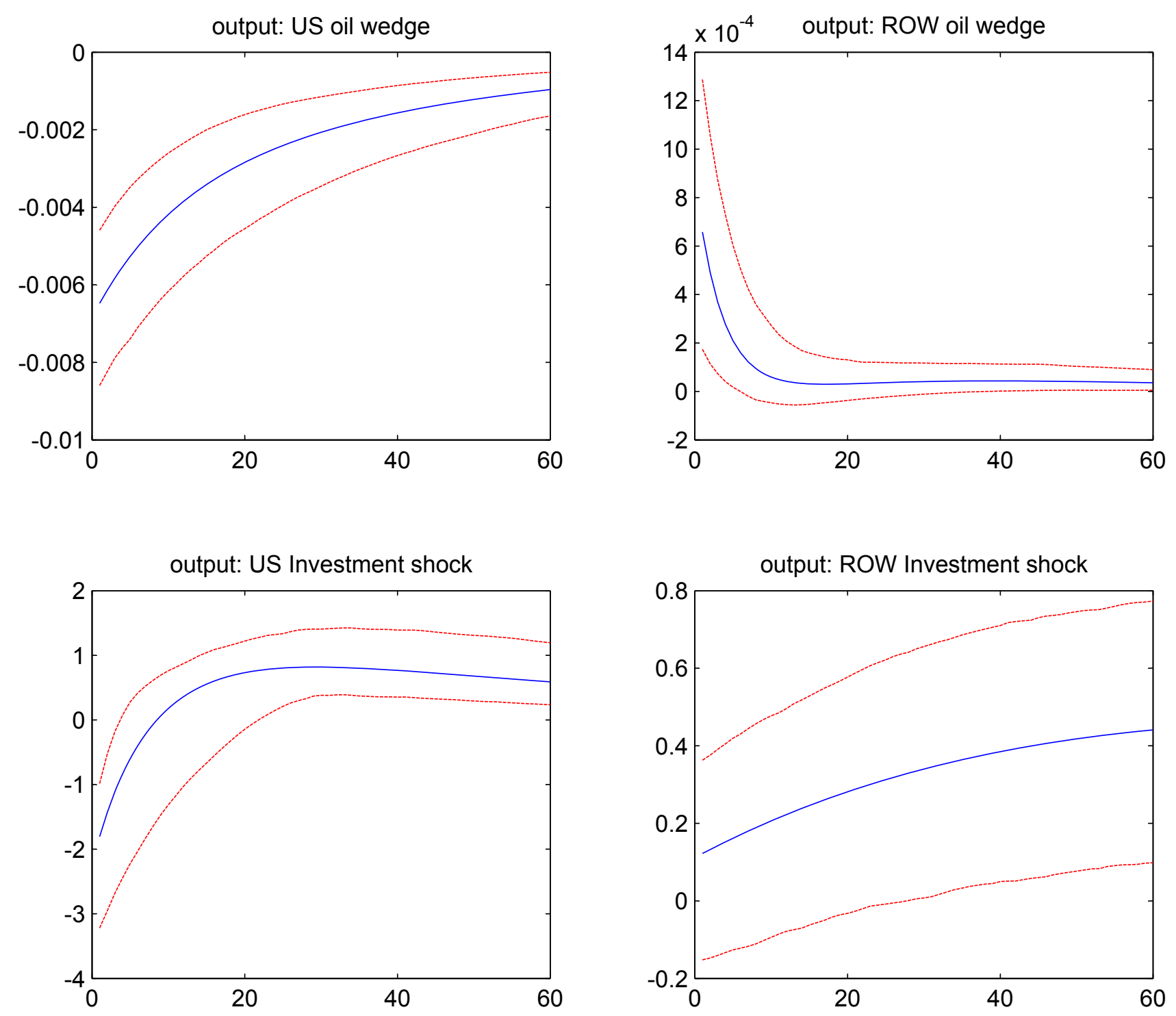
Figure 5A. Historical Decomposition of Real Oil Price: Supply and Demand Shocks
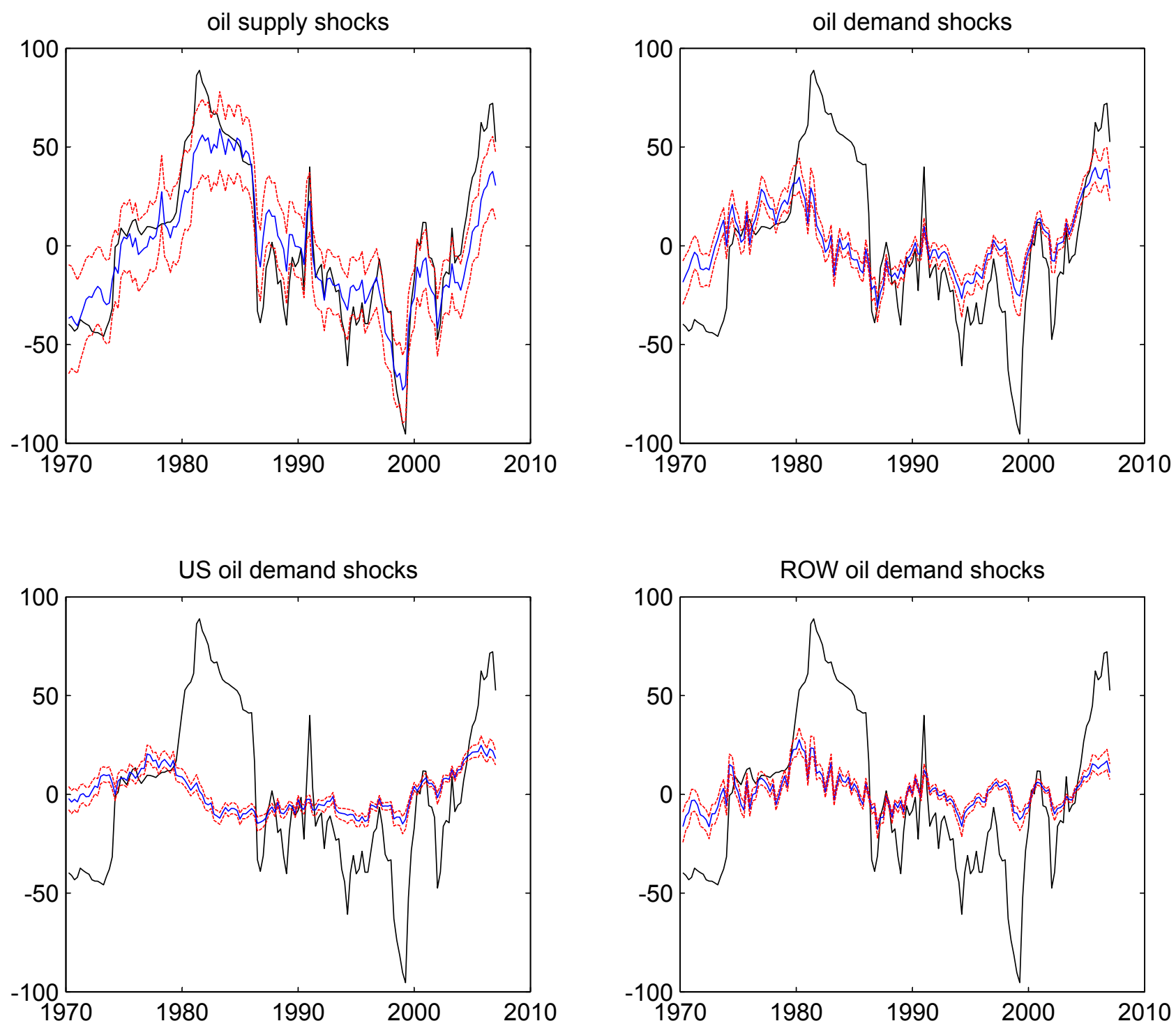
Figure 5B. Historical Decomposition of Real Oil Price
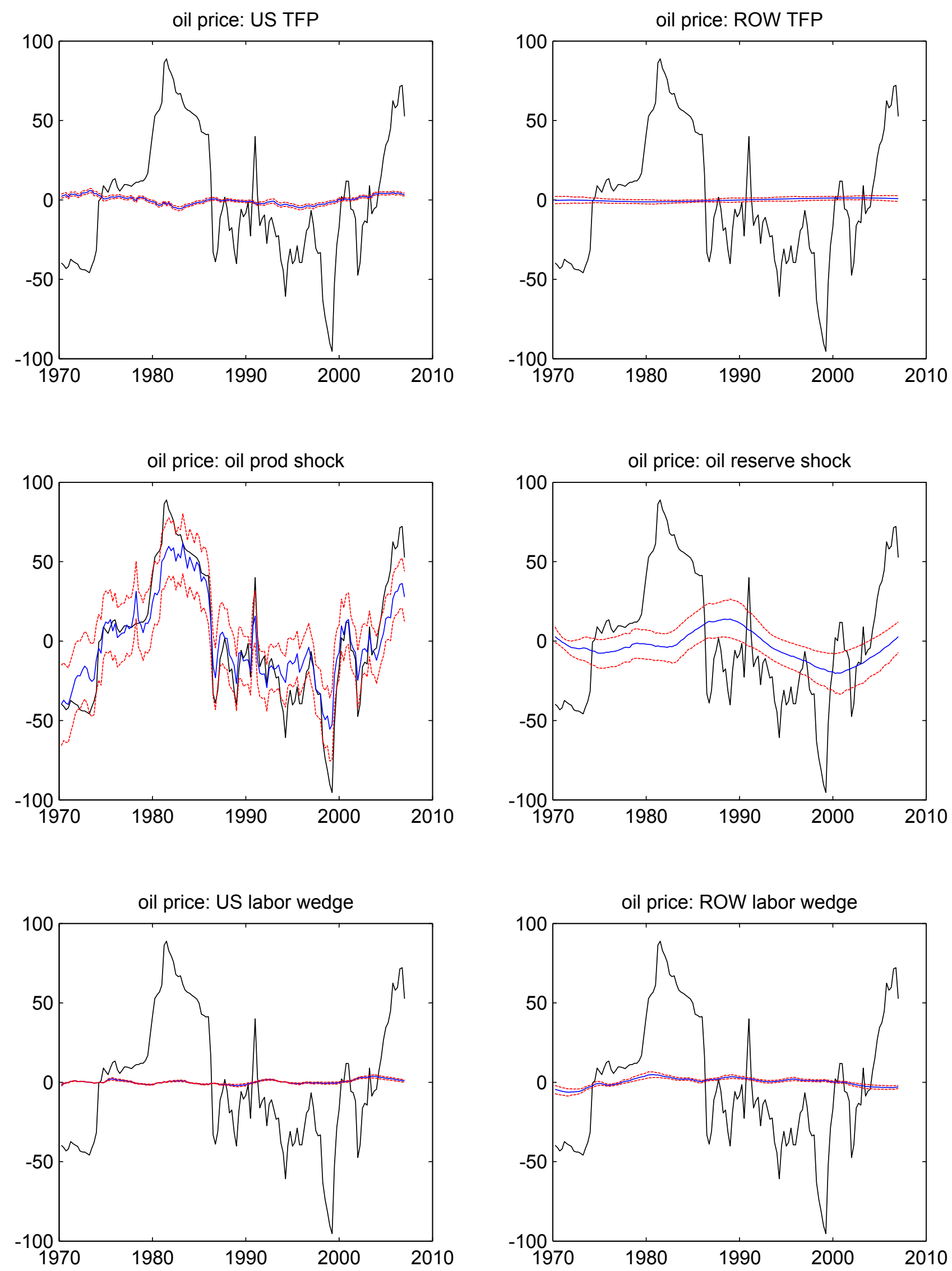
Figure 5C. Historical Decomposition of Real Oil Price
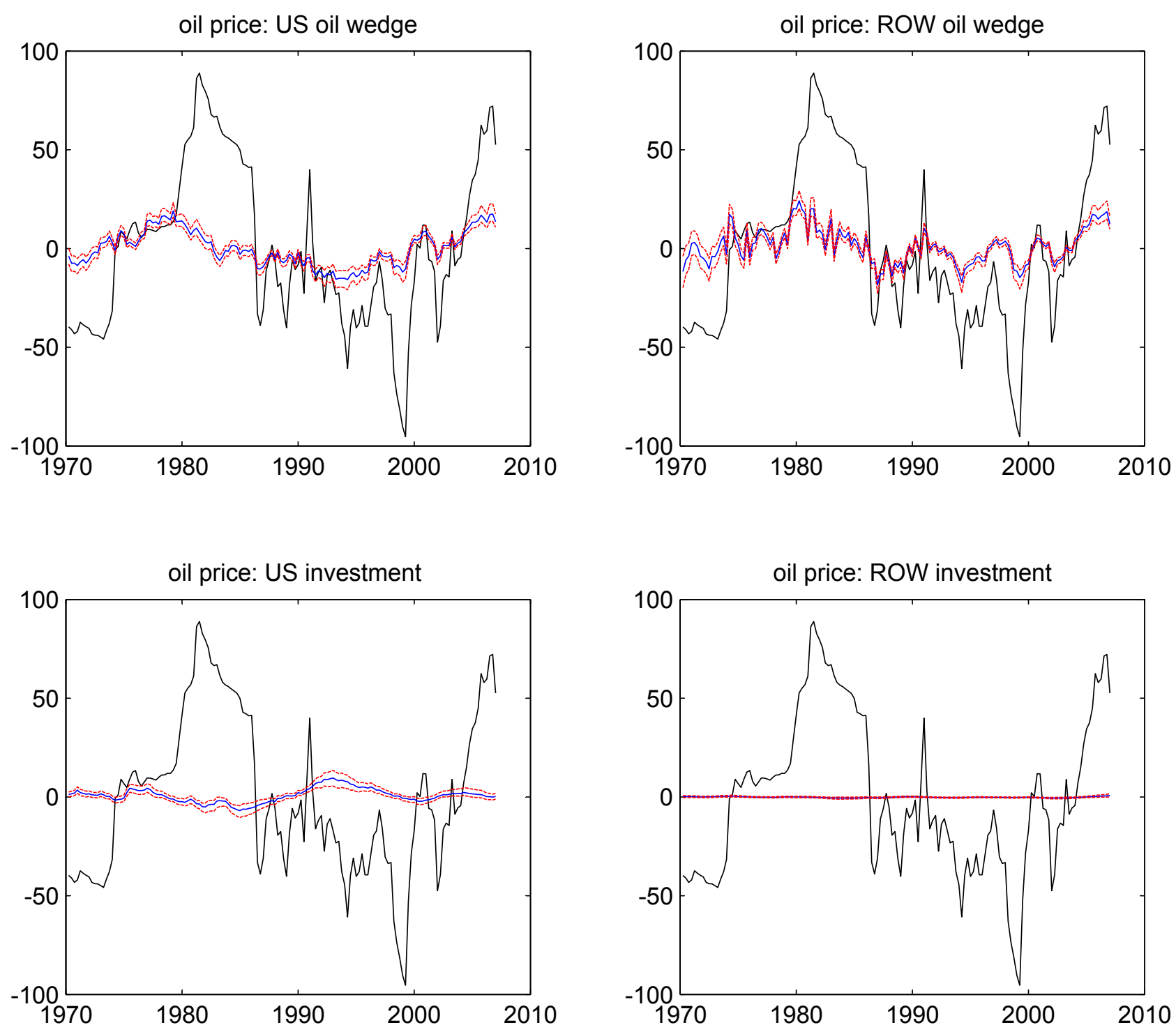
Figure 6A. Historical Decomposition of U.S. GDP: Contributions of Oil, U.S. and ROW shocks
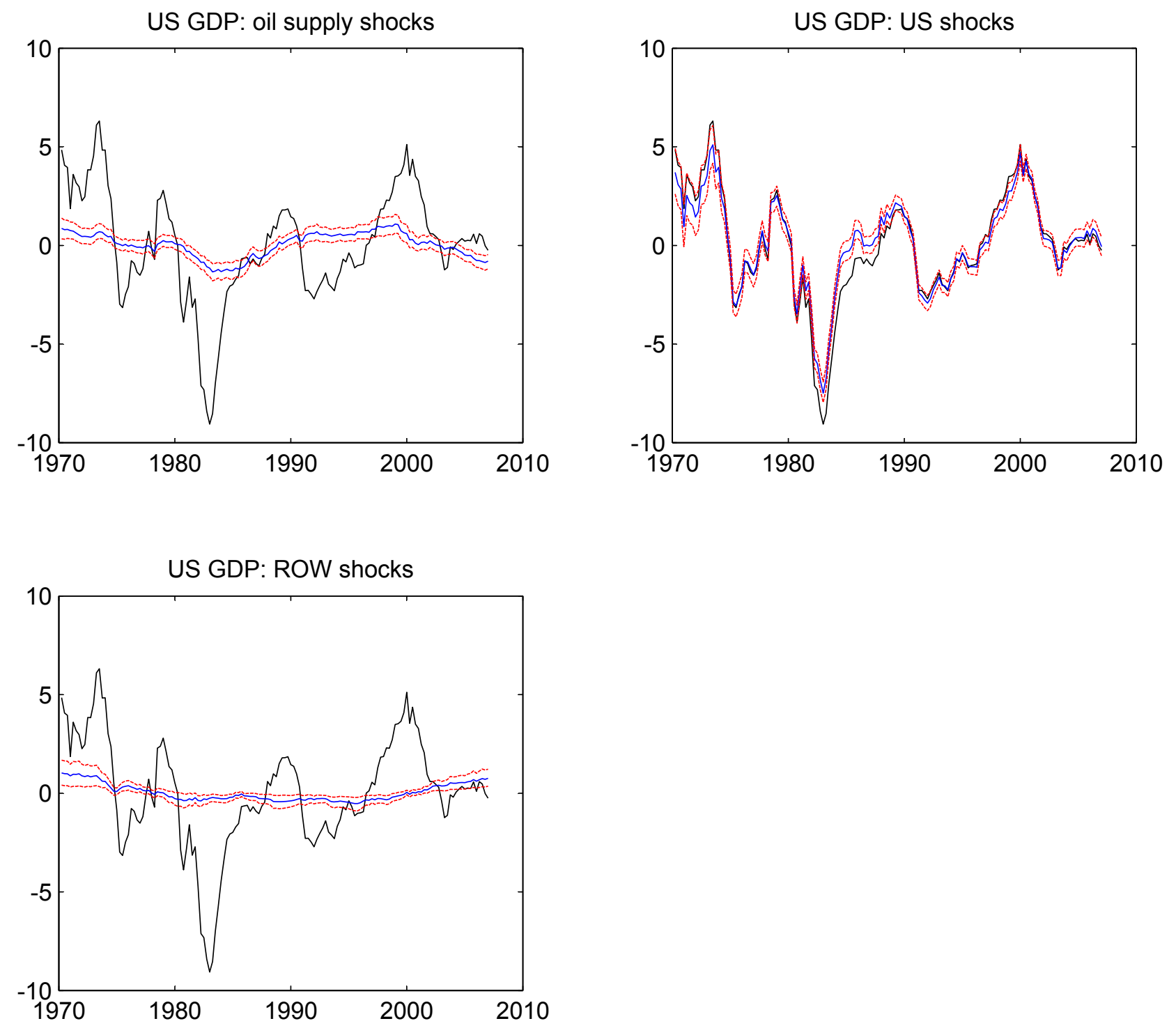
Figure 6B. Historical Decomposition of U.S. GDP
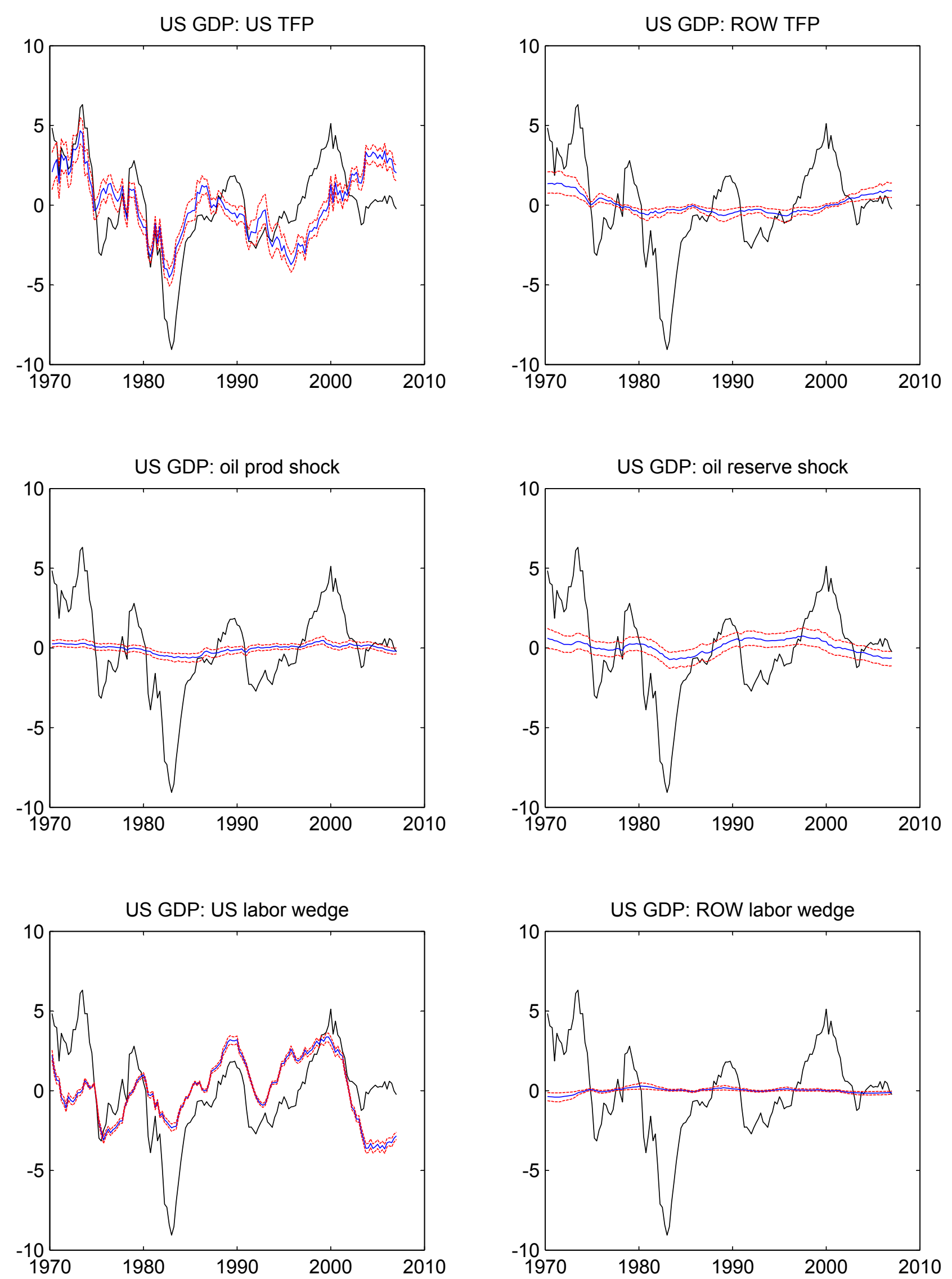
Figure 6C. Historical Decomposition of U.S. GDP
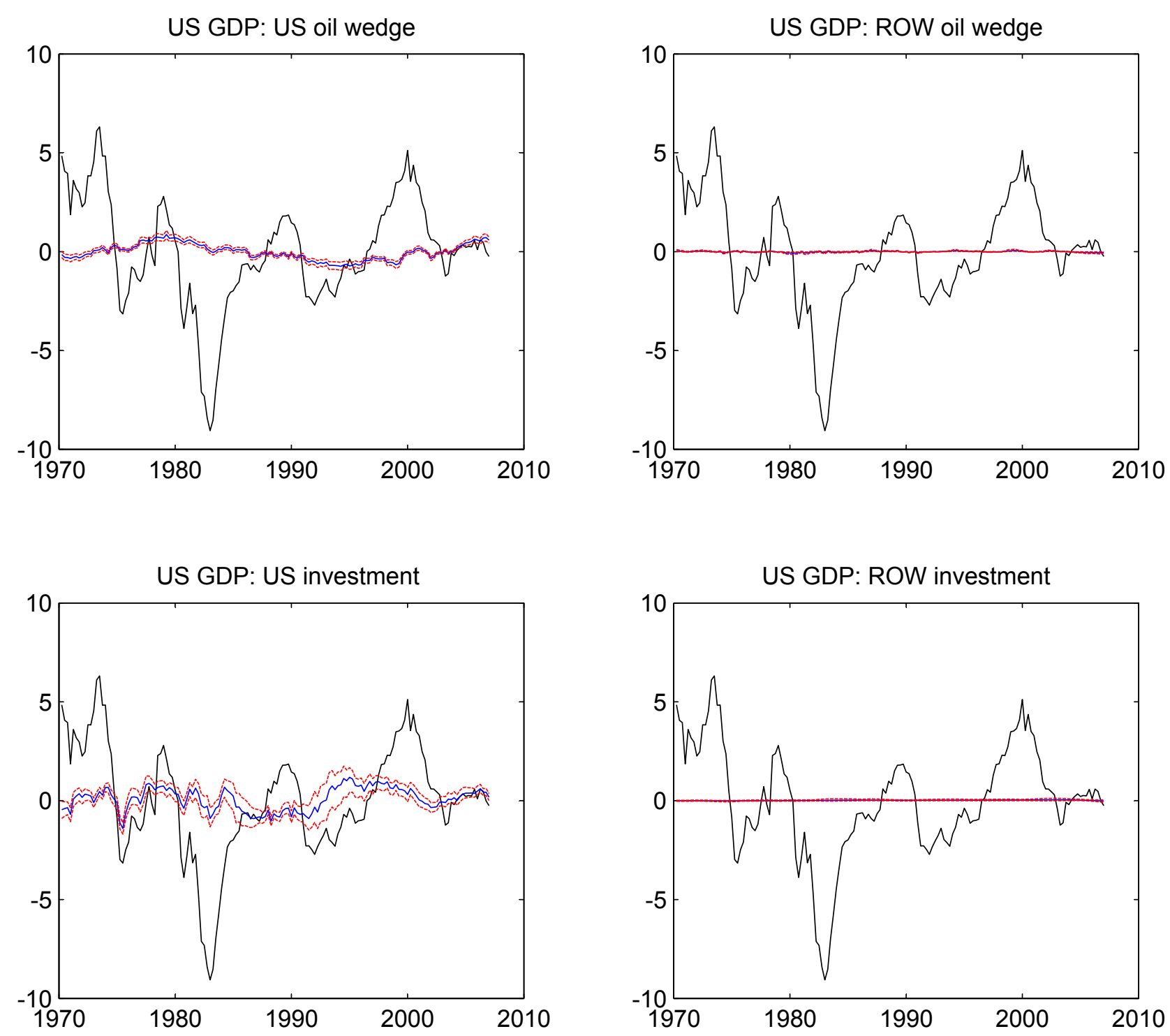
Figure 7. Historical Decomposition of ROW GDP
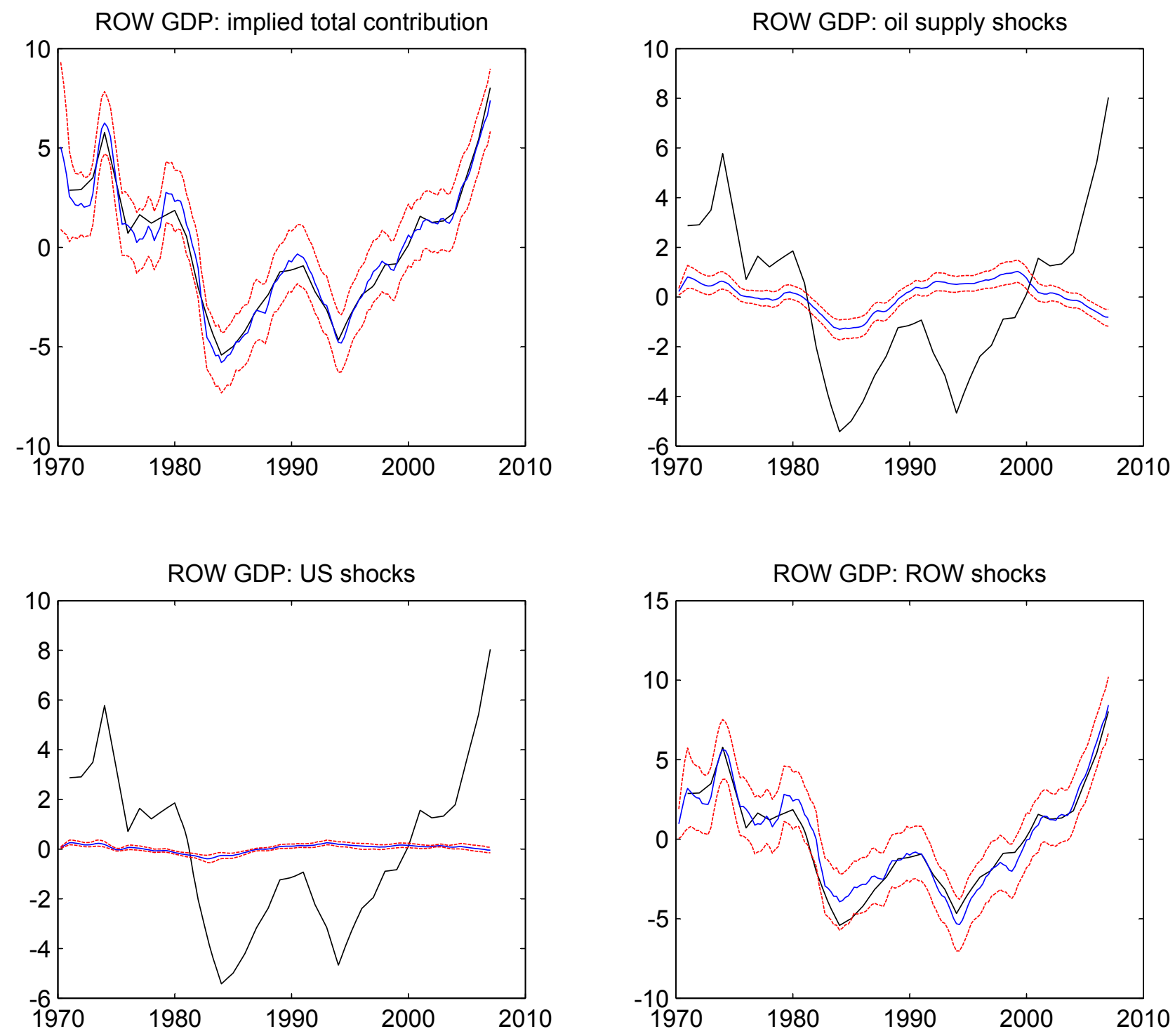